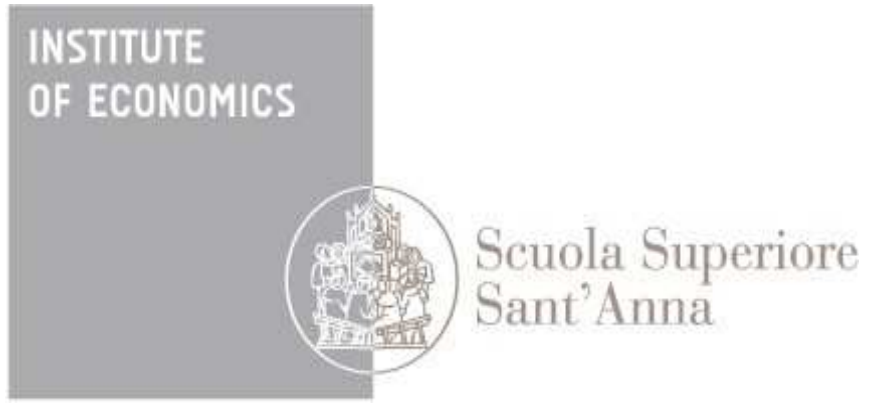

LEM | Laboratory of Economics and Management

Institute of Economics

Scuola Superiore Sant'Anna

Piazza Martiri della Libertà, 33 - 56127 Pisa, Italy ph. +3905088.33 .43$

institute.economics@sssup.it

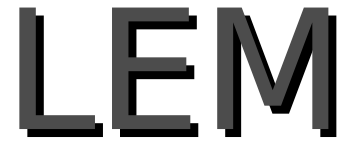

Working Paper Series

\title{
Persistent high-growth firms in China's manufacturing
}

\author{
Daniele Moschella ${ }^{\circ}$ \\ Federico Tamagni ${ }^{\circ}$ \\ Xiaodan $\mathrm{Yu}{ }^{\circ}$
}

'Institute of Economics, Scuola Superiore Sant'Anna, Pisa, Italy 


\title{
Persistent high-growth firms in China's manufacturing*
}

\author{
Daniele Moschella, Federico Tamagni, and Xiaodan $\mathrm{Yu}^{\dagger}$ \\ Scuola Superiore Sant'Anna, Pisa, Italy
}

\begin{abstract}
This article explores the association between persistence of high-growth and crucial dimensions of firm structure and performance (productivity, profits, investment patterns, innovation and financial structures) to shed light on what makes a persistent high-growth firm. We employ a multidimensional definition of an high-growth firm that simultaneously accounts for growth of sales and employment, and design an empirical strategy that seeks to capture the "long-run" ability of high-growth firms to replicate their high-growth performance over time. Exploiting a large panel covering the period of the China's miracle, we find that none of the considered firm attributes stands out as distinctive feature of persistent high-growth. This finding casts doubts on the long-run contribution of high-growth firms, in turn challenging the long-run effectiveness of policies supporting the creation and expansion of such firms.
\end{abstract}

JEL codes: D22, D24, L26

Keywords: Entrepreneurship, high-growth firms, persistent high-growth firms, China

${ }^{*}$ We thank Giovanni Dosi and Jiasu Lei for helping with the study and giving insightful suggestions. We thank participants to the International Workshop \& Small Business Economics Special Issue on Entrepreneurship in China, Beijing, October 2016. We thank Zoltan Acs, Haifeng Qian, Jiangyong Lu and Canfei He for their insightful suggestions. We gratefully acknowledge the support by the European Union Horizon 2020 Research and Innovation programme under grant agreement No. 649186 ISIGrowth. Daniele Moschella received financial support by the Italian Ministry of Education, University, and Research under the SIR Programme (project code RBSI14JAFW). The usual disclaimer applies.

${ }^{\dagger}$ Main author for correspondence: Xiaodan Yu, Scuola Superiore San'Anna, Pisa, Italy. Postal address: Institute of Economics, Scuola Superiore Sant'Anna, Piazza Martiri 33, 56127, Pisa, Italy, E-mail: xiaodan.yu@santannapisa.it 


\section{Introduction}

The identification of the characteristics that make a firm able to provide extraordinary contribution to growth and employment creation is at the center of the attention of practitioners and policy makers around the world. Achieving high growth, especially in terms of sales and market shares, is often considered as one of the most important factors in entrepreneurial orientation (Covin et al., 2006), and policies to support the creation and the performance of gazelles, i.e. small, young and, more generally, high-growth firms are adopted in several countries. They have also received new attention as a driver of economic recovery and employment growth after the global crisis (see Birch and Medoff, 1994; Davidsson and Henrekson, 2002; Acs and Mueller, 2008; Henrekson and Johansson, 2010; Acs et al., 2011; Coad et al., 2014).

The academic literature on high-growth firms is vast, with contributions coming from different research areas, at the intersection between firm-industry dynamics, entrepreneurship and management studies. In brief, and without claiming to be exhaustive, the development of this literature proceeded mostly through empirical studies, seeking to identify the conditions that ease or hamper the creation and the development of high-growth firms, both in terms of structural conditions of the environment in which firms operate (institutional and geographical factors, characteristics of input, output and credit markets, role of network and externalities, public policies of various kind) and in terms of the firm-specific characteristics that associate with high-growth events. Of course, the empirical efforts were guided by an equally large number of theoretical contributions to the conceptualization of types and modes of entrepreneurship - from Schumpeter's view on the different sources and modes of entrepreneurial innovation across industries, to the classical works by Baumol (1990) (see also the more recent Baumol (2010)) -, as well as by more recent models of firm-growth and industry dynamics with heterogeneous firms, from very different traditions, such as neoclassical models of equilibrium dynamics (as in Jovanovic, 1982; Hopenhayn, 1992; Ericson and Pakes, 1995; Luttmer, 2007; Clementi and Hopenhayn, 2006), or evolutionary disequilibrium theories (as, among others, in Nelson and Winter, 1982; Winter, 1984; Dosi et al., 1995; Metcalfe, 1998; Bottazzi et al., 2001), in turn sharing with management scholars the notion of routines and dynamic capabilities of the firm as the key drivers of sustained comparative advantage and growth over time (Teece and Pisano, 1994; Teece et al., 1997; Dosi et al., 2001; Pisano, 2015).

We now know a lot about the possible role of a number of institutions and policy measures such as taxation of entrepreneurial income, incentives for wealth accumulation, wage-setting and labor market 
regulation, geographical knowledge spillovers (see, among others, Davidsson and Henrekson, 2002; Acs and Mueller, 2008; Garsaa and Levratto, 2015), while a number of firm-specific attributes have been studied as distinguishing features of high-growth firms (see Coad and Hölzl, 2012, for a more extensive review). In this respect, the meta-analysis of the literature conducted in Henrekson and Johansson (2010) identifies the established stylized facts that high-growth firms tend to be younger, smaller and ubiquitous in all industries, confirming the seminal study by Schreyer (2000). A recent debate centers around the relative role of the two key demographic characteristics, namely size and age, as key drivers of high-growth and extraordinary employment creation. While most studies identify high-growth firms as small and young, Henrekson and Johansson (2010) emphasize that larger gazelles are also important job contributors in absolute terms. Newness or young age was found as the key characteristic supporting high employment growth in the US before the 2000 by Haltiwanger et al. (2013), although the contribution of startups and young businesses declined in the following 10 years (see Decker et al., 2016), whereas, on the contrary, Acs et al. (2011) find that the average high impact firm is around 25 years old when it makes a significant contribution to the economy (see also Lawless (2014) on Irish firms and Grazzi and Moschella (2016) on Italian firms).

Two further characteristics that seem to play a major role in high-growth patterns are export status and ownership structure. From the internationalization and trade perspective, we know that many high-growth firms are indeed exporters and their strategies are globally oriented (Robson and Bennett, 2000). Also, there is evidence that different ownership types associate with differential growth performance: although the average growth rates of domestic and foreign firms do not necessarily differ (see the meta-analysis in Bellak, 2004), state-owned firms usually perform worse than private firms, and foreign-owned firms are more likely to exhibit fast-growth (Beck et al., 2005).

Beyond this largely demographic characterization of high-growth firms, theories of firm-industry dynamics points at wide heterogeneities in productivity and profitability, mediated by financial conditions and innovation capacity as the crucial structural dimensions of performance that sustain growth (see Dosi et al., 2007). In the empirical literature connecting such structural dimensions of performance with high-growth, innovativeness occupies a disproportionate share of available studies, relating high-growth to different innovation activities undertaken at the firm level, such as $R \& D$, patenting, product vs. process innovation, external sourcing of knowledge, and other indicators usually available through innovation surveys (see, among others Coad and Rao, 2008; Hölzl, 2009; Stam and Wennberg, 2009; Segarra and Teruel, 2014; 
Bianchini et al., 2016), also exploring the mediating role of age in connecting innovation and growth (see, e.g., Huergo and Jaumandreu, 2004; Coad et al., 2016). Results show that innovative efforts are indeed important for the growth performance of firms in the top quantiles of the growth rates distribution, while they are not crucial determinants of growth of the average firm (see Audretsch et al., 2014, for an exhaustive survey).

The role of other structural characteristics, such as efficiency, availability of profits, patterns of investment and access to finance as determinants of high-growth is less investigated. Concerning productivity results are mixed. Du and Temouri (2015) find, for the UK, that firms in both manufacturing and services sectors are more likely to become high-growth firms when they exhibit higher productivity growth, and Bianchini et al. (2017) show that high-growth firms are more efficient in Italy and Spain; on the other hand, Daunfeldt et al. (2010) detect an insignificant or even negative association between productivity growth and high-growth for Swedish firms. There is some evidence that high-growth firms are more profitable than other firms (see Coad et al., 2011; Bianchini et al., 2017), although not many studies are available on the subject. Profits and other proxies of internal finance, such as cash flow, are extensively analysed within the literature on financial constraints to investment and growth. In fact, notwithstanding that internal finance and credit rationing are recognized as critical to the growth performance of young and small enterprises (see Oliveira and Fortunato, 2006; Bottazzi et al., 2014, for reviews), only few studies relate financial conditions and investment dynamics to high-growth. Bianchini et al. (2017) show that high-growth firms tend to face higher interest burden and to rely more on external credit than on their own resources, a finding that may be interpreted as a signal of past ability to access credit, but also as a worrying feature for future viability of the business.

Against this background on the characteristics and drivers of high-growth, in this paper we contribute to a more recent literature that investigates the ability of high-growth firms to sustain their extraordinary growth performance consistently over time. The main motivation for this switch of perspective is that persistent high-growth firms represent much more promising candidate to provide substantial contributions to economic performance of sectors and countries than "simple" high-growth firms that exhibit just one or two spurts of high-growth. Indeed, the great deal of scholarly and policy attention devoted to the creation of and support to high-growth firms implicitly assumes that high-growth firms are an engine of growth that lasts over time. Policy makers, in particular, are more likely to search for firms that continuously create high value and large employment creation, than they are to support the experimentation and private 
returns of some firms that grow spectacularly for just a short period of time.

We know very little about the persistence of high-growth events, however, and even less about what makes a firm a persistent high-growth firm. Very few studies indeed investigate these issues. On the one hand, some studies even challenge the very existence of persistent high-growth firms. Hölzl (2014); Daunfeldt and Halvarsson (2015) show that high-growth firms are most likely to be "one-hit wonders" that do not replicate their high-growth over time, echoing theories of firm growth as essentially stemming from luck (Barney, 1997), while Delmar et al. (2003) and Capasso et al. (2014) show that persistent outperformers and "super relative growers" do exist, although they are relatively rare. On the other hand, even when there is evidence that persistent high-growth firms do exist, they are usually characterised just in terms of size and age, with mixed results. Coad (2007) and Coad and Hölzl (2009) find that small highgrowth firms display negative growth autocorrelation, whereas large and established companies achieve smoother dynamics. Conversely, Capasso et al. (2014) conclude that persistent outperformers are more often present among micro firms.

We provide a twofold contribution to the study of high-growth persistence. Our main research question is to address whether more structural factors, such as productivity, profits, investment, financial conditions and innovativeness, stand out as distinguishing features of persistently high-growing firms, beyond demographic characteristics. To our knowledge, there are only a couple of papers addressing a similar question. Guarascio and Tamagni (2016) measure high-growth persistence in terms of short-term (yearly) autocorrelation of sales growth in the top quantiles of the growth rates distribution in a sample of Spanish firms, showing that the latter is not affected by persistence in innovation. Bianchini et al. (2017) provide a more comprehensive analysis, addressing a set of firm characteristics similar to the one we consider in this paper, including productivity, profitability, intangible assets and financial conditions, beyond size and age. They identify persistent high-growth firms over a relatively long-run (4 years) perspective, and show that persistent high-growth firms do not differ from "simple" high-growth firms along any of the dimensions of structure and performance, in a sample of firms active in manufacturing and services in Italy, Spain, France and the UK. We share with Bianchini et al. (2017) the emphasis on the need to look at relatively long-run perspective, beyond 1-year auto-correlations, but provide a different econometric framework that allow to estimate whether firm structural characteristics contribute to the probability that an high-growth firm remain high-growth over a relatively long span of time.

Second, we address our main question in the context of Chinese manufacturing firms. This is an 
important contribution per se, since the literature not only on high-growth persistence, but on high-growth firms more generally is dominated by studies on advanced economies. Analysis of high-growth dynamics in developing economies are rare, and the few exceptions are so far more focused on the institutional obstacles to entrepreneurship and growth that may affect those countries, such as under-development of infrastructure, financial, legal and institutional obstacles. Krasniqi and Desai (2016), for example, offer country-level analysis of the importance of formal and informal institutions on the share of high-growth firms in the economy, across 26 transition countries. Firm-level analysis in developing context is even more scant, often for lack of data, but started recently to appear. Goedhuys and Sleuwaegen (2010)'s study of Sub-Saharan countries confirms the importance of technology and infrastructure (access to internet from own website, in particular) for high-growth entrepreneurship. Santi and Santoleri (2016) tend to confirm the importance of product and process innovation for top-growing Chilean firms.

In this perspective, the case of Chinese manufacturing, and in particular the period covered by our data (1998-2007), corresponding to the years of the extraordinary materialization of the "China miracle", represent an extremely interesting test-bed for understanding the contribution of firm's structural characteristics to high-growth persistence. That phase of unprecedented expansion was indeed boosted by reforms and direct policies undertaken by the Chinese authorities favoring the development of virtuous dynamism in the economy, supporting new entrepreneurship and private firms, although within the boundaries of a state-managed economy. Understanding the factors distinguishing persistent high-growth firms - which are likely to capture the dynamism of "true entrepreneurship" - from simple one-hit wonders in that period might also help to facilitate policy measures to sustain the recovery of the Chinese economy after the global crisis, and the process of Chinese economic catching-up in the long-run.

In Section 2 we provide an overview of entrepreneurship and high-growth dynamics in the context of China. In Section 3 we present and motivate the empirical framework that we adopt to assess the interplay between persistence of high-growth and firm characteristics. Section 4 shows descriptive evidence on highgrowth, high-growth persistence and evolution of main firm characteristics. In Section 5 we present our main findings on the influence of structural firm characteristics upon the probability to persistently remain high-growth, while in Section 6 we dissect the specific role of age, size and state-ownership. Section 7 concludes. 


\section{The Chinese context}

The extraordinary performance of the Chinese economy, especially over the period that we consider in this study, has obviously attracted attention of scholars and policy makers. Increasing availability of microdata at the firm level allowed for a characterization of the key features of industrial dynamics in that period, highlighting the role of virtuous transformation and learning of domestic firms, the differential contribution of state-owned vs. private firms, also regarding access to finance and the role of innovation in survival and growth (see Yu et al., 2015b; Guariglia et al., 2011; Zhang and Mohnen, 2013). Indeed, the "China miracle" entailed a major process of increasing returns through learning and accumulation of knowledge and technological capabilities based on firms that are highly heterogeneous, in terms of all the dimensions of firm performance and characteristics that we analyse in this study (Yu et al., 2015b; Yu et al., 2015a).

Explicit consideration of patterns and determinants of high-growth dynamics has not received attention, however. Most of existing literature frames the dynamism of the Chinese economy around the concept of entrepreneurship, as those creations and newness initiated by Chinese citizens or domestic firms over the last 15-20 years, and the socio-political transformations that sustained them (Yang and Li, 2008; Li, 2013).

The development of entrepreneurship in China went through three phases (Li, 2013), characterized by the emergence and prominent role of different types of new firms: the first stage (1978-1992) sees the birth and flourishing of township-and-village enterprises, and the initial appearance of private firms; the second stage (1992-2000) features the rapid growth of non-public firms, promoted by the first signals of political acceptance of the private property (the Deng Xiaoping's 'South Tour' in 1992) and the related constitutional amendment in 1999; in the third stage (2000-present), increasing supportive and encouraging policies have been issued to channel private investments, promote small and medium enterprises and to protect private property. A number of studies on Chinese entrepreneurship extensively focus on the association between the phases of entrepreneurial development and liberalization policies, such as the removal of institutional

barriers to private ownership, or easing the access to key resources (finance, labour and technology) for private firms and SMEs (Chang and MacMillan, 1991; Li and Matlay, 2006).

Among the three types of entrepreneurship that usually coexist within developing countries - subsistence, catch-up and frontier entrepreneurship (see Hobday and Perini, 2009; Huang, 2010) -, the vast majority of Chinese entrepreneurships are of the catch-up type. They usually engage in replicative activ- 
ities, copying and producing at competitive costs innovations introduced by others, as it is the case, for instance, with Wanxiang (an automobile supplier) and Geely (the firm that just acquired Volvo). They considerably contribute to the economy through market expansion (within existing areas) and job creation, although they introduce breakthroughs in science and technology at a much lower pace than frontier entrepreneurship firms do.

The prevalence of catch-up firms warns against the potentially misleading implications that may arise from an exclusive focus on start-ups and small firms. As argued by Hobday and Perini (2009), there is a spread mis-conception of the function of new and dynamic firms in catching-up economies: their primary role is to enable technology transfer, learning, and incremental innovation, rather than to trigger 'Schumpeterian dynamics' leading to new product and process development, which is instead the main role of entrepreneurship in advance economies. And, indeed, the evidence on successful firm-level growth from China and other Asian countries shows that large firms, SMEs, and multinational corporations all play a role in entrepreneurial progress. In this sense, our study of the drivers of high-growth and its persistence could be more revealing than the usual focus the literature on China has traditionally devoted to small, innovative start-ups. The extensive dataset covering a large part of Chinese manufacturing represents an ideal setting to ground the understanding of high-growth persistence upon the general background of the rapid catching-up of the Chinese economy.

\section{Persistence of high-growth and firm characteristics: an empirical framework}

Our key research question is to shed light on whether a set of firm characteristics, which are theoretically considered as important determinants of firm growth, display in turn an empirical association with the ability to replicate high-growth performance over time. Addressing this question is not trivial, since the few previous studies concerned with persistence of high-growth do not offer a shared empirical framework. There exist different, and not at all consistent definitions of what an high-growth firm is. Similarly, there is no consensus on the very notion of persistence one should adopt, beyond a generic agreement that one should look at firms that are able to maintain their high-growth status, however defined, consecutively over a certain number of years. Definitions and empirical settings are inevitably constrained by the type and nature of the data that different researchers have access to. In this Section, after a brief description 
of the data, we present and discuss our baseline empirical model, and introduce the variables adopted to proxy for key firm characteristics.

\subsection{Data}

The analysis exploit the firm-level data collected by the Chinese National Bureau of Statistics (NBS), to which we have access for the period spanning the years 1998-2007. The original dataset is a standard business register type of data, largely used in previous studies on Chinese firm-industry dynamics (see, among others, Hu et al., 2005; Fu and Gong, 2011; Yu et al., 2015b). It includes all industrial firms with sales above 5 million RMB (around \$US 600,000), while firms employing less than 8 employees are not recorded, since Chinese firms below that threshold operate under a completely different legal system (see Brandt et al., 2012) The data cover mining, manufacturing and public utilities, and each firm is assigned to a sector according to the 4-digit Chinese Industry Classification (CIC) system, that closely matches the Standard Industrial Classification (SIC) employed by the U.S. Bureau of Census. ${ }^{1}$ We focus on manufacturing firms only, and apply a few cleaning procedures to the original data, as suggested in Yu et al. (2015b) in order to eliminate visible recording errors. ${ }^{2}$ The final version of the data at our disposal corresponds to the "China Micro Manufacturing" (CMM) panel used in Yu et al. (2015b). Next, since measuring high-growth and its persistence, as it will become clear in the following, requires to follow the same firms over a reasonably long time span, we focus on those continuing firms that are present in the data over the entire period 1998-2007. The resulting balanced panel consists of working sample of 22,988 manufacturing firms.

\subsection{Empirical model}

Correlating high-growth persistence with firm attributes involves three problematic issues. First, one needs a definition of high-growth firm. But this is not an easy step, as indeed the literature suggests a number of identification criteria, that differ under several respects. Different size proxies are employed, usually distinguishing between employment and sales, respectively looking at growth in terms of "physical capacity" or in terms of "success on the market". The two growth processes do not necessarily map one into the other, and their determinants can be arguably different, with employment growth more related

\footnotetext{
${ }^{1}$ In 2003, the classification system was revised: some sectors were further disaggregated, while others were merged together, but consistency over time is ensured by adopting the harmonized classification proposed in Brandt et al. (2012).

${ }^{2}$ Essentially, we just dropped few firms with negative values in output, sales, value added, fixed assets, and cost of labour.
} 
to labour market dynamics, and sales more related to industrial dynamics. Further, there is not a unique criterion to define "how high" an high-growth jump must be to qualify a firm as high-growth. Different studies distinguish between either absolute or relative extraordinary growth events. This makes a difference, since absolute growth (defining, for instance, as an high-growth firm a firm hiring 200 employees or selling 1ML dollars more) implies a bias toward larger firms, while relative growth (e.g., defining as high-growth a firm that doubles its size) allows more small-micro firms to also qualify as high-growth. And, of course, the different thresholds used in both absolute and relative growth also matter. Not unrelatedly, it also matters the fact that one usually tries to compare the jump of each firm with the growth patterns of a relevant reference group (e.g., firms in the same sector): high-growth often is intended and measured as being in some top percentile of the distribution of growth rates across the firms in the reference group, but results may vary, of course, depending on which percentile one looks at (top 20\%, or top decile, for instance). In particular, one has to balance between the need to apply stringent thresholds that more likely define the group of "genuinely top performers", and the possibility that too stringent thresholds (say top 1\%) end up identifying a too small number of high-growth firms, preventing any meaningful statistical comparison with other firms. Finally, different approaches are followed regarding the time span over which a high-growth event is considered. Starting from the known stylised fact gathered in the empirical literature on Gibrat's Law stating that firm size is a quasi random-walk, and thus growth growth itself is quite random, most studies evaluate high-growth jumps averaging over some years, typically 3-5 years. Still, since this practice may absorb most of the time-span of the typical panel dataset available (usually spanning around 10 years), it is not uncommon that high-growth is also measured on a yearly basis.

The last consideration links directly to the second major issue we need to tackle, concerning the different notions of persistence that are implicitly or explicitly employed in the literature. Indeed, once a definition of high-growth is chosen, there are different ways to evaluate whether a firm replicate its highgrowth status over time. The shared basic intuition is that a persistent high-growth firm must experience high-growth consecutively for some time steps. Yet, different empirical operationalization of this notion coexist. A first approach is to estimate the transition probabilities across different quantiles of the growth rates distribution, usually over one-to-three years transitions. Another approach is to estimate quantile regressions to evaluate the degree of growth autocorrelation in the top quantiles of the growth rates distribution, usually taking one or two yearly lags of growth on the right hand side. Both methods allow to quantify the degree of persistence in the data, averaging across firms that over time jumps in and out 
from top quantiles, but they do not provide an identification of a group of persistent high-growth firms, however. Moreover, the implicit notion of persistence is essentially of a short-run nature: both approaches define high-growth on a yearly basis, and look at the probability to remain high-growth one, two or three years later. Of course, the main reason is that researchers do not usually have long-in-time panels allowing to capture a more genuinely, long-run definition of persistence of high-growth status. The issue is made explicit and at least partially tackled, within the limitation of their data, in the recent study by Bianchini et al. (2017), that define a group of persistent high-growth firms as those remaining in the top decile of yearly growth rates distributions for at least 4 out of 5 years covered by their data.

A third, and final issue pertains to design an empirical strategy to eventually tackle the key question: once a suitable identification of persistent high-growth is chosen, how can one identify whether they differ in terms of firm-level attributes ? In this respect the available literature, as mentioned, is at its initial stage, providing essentially only two alternatives. A first approach, within the studies that exploit quantile auto-regressions in top quantiles of growth as the methodology to address high-growth persistence, is to compare the autoregressive coefficient across groups of firms with different firm characteristics, essentially age and size. But, again, this gives an idea about whether these firm attributes have some relation with short-run persistence of high-growth. Bianchini et al. (2017), instead, estimate the effects that a larger set of firm characteristics have on the probability to belong to the group of firms that they a-priori define as persistent high-growth firms, over to somewhat longer-run horizon discussed above.

In the absence of a commonly accepted framework, we design an empirical strategy that tries to balance the several trade-offs emerging from previous studies, and inevitably within the limitations imposed by the data available to us.

To this end, we divide the 10 years spanned by our data into sub-periods, identify high-growth status in terms of the average growth experienced by each firm vis-à-vis other firms in each sub-period, and, finally, we capture the "effect" of different firm attributes on high-growth persistence by looking at whether key firm attributes display any statistically significant association with the probability that a firm remains high-growth over two consecutive sub-periods.

More specifically, we proceed as follows. First, we distinguish three non-overlapping sub-periods: period 1 (1999-2001), period 2 (2002-2004) and period 3 (2005-2007). Second, we compute the within-period average growth rate for each firm: $g_{i, 1}=\left(s_{i, 01}-s_{i, 98}\right) / 3, g_{i, 2}=\left(s_{i, 04}-s_{i, 01}\right) / 3$ and $g_{i, 3}=\left(s_{i, 07}-s_{i, 04}\right) / 3$, where firm size $S_{i, t}$, is measured as either sales or number of employees, and $s_{i, t}=\log \left(S_{i, t}\right)-\frac{\sum_{i \in j} \log \left(S_{i, t}\right)}{N}$, 
such that $s_{i, t}$ is $(\log )$ firm size normalized by the average $(\log )$ sizes computed across the $N$ firms active in the same 2-digit sector $j$ of firm $i$ in year $t .{ }^{3}$ Based on these average growth figures, we define, in each period, an high-growth status dummy (HG) that takes value 1 for all firms falling into the top $20 \%$ of the within-period distribution of average growth rates, in terms of at least one of the two growth measures (employment or sales).

By considering both sales and employment growth in the definition of the HG group we provide a multidimensional characterization of the growth processes of firms, accounting at the same time for different size proxies employed in the literature and reflecting the idea that no single "best" indicator of size exists. The multidimensional perspective was already pointed out in Delmar et al. (2003), where HG firms are defined as those performing in the top $10 \%$ of six growth indicators, and recently re-affirmed in Daunfeldt and Halvarsson (2015) and Bianchini et al. (2017), employing a "mixed" measure of HG that, similarly to us, combines growth of employment and growth of sales. Further, our definition implicitly defines HG firms in terms of their relative growth, thus allowing for a more equal treatment of small-medium-large firms as compared to absolute growth, as in, for instance, Delmar et al. (2003); Capasso et al. (2014); Daunfeldt et al. (2014). Moreover, by considering annualized average growth over 3 years we account for the fact that a single big jump in size in one year does not seem enough to characterize firms that indeed consistently outperform the others. This is fairly recognized in the literature, as mentioned, although the time windows considered span from 3 to 6 years, depending on the available data. Three-year averages are used in Daunfeldt et al. (2014); Hölzl (2014); Daunfeldt and Halvarsson (2015), and are consistent with the OECD definition of HG firms. The latter definition (see, for example, Hölzl (2014)) identifies as HG the firms that achieve an annualized growth rate of at least $20 \%$ during a 3-year period and have an initial size of at least 10 employees. We did not apply this definition since it also tend to exclude relatively smaller firms. Lastly, the choice of a $20 \%$ threshold is somewhat arbitrary, although comparable with other studies on other countries. We experimented with a more stringent definition taking the top $10 \%$, but the number of firms classified as HG dropped significantly, preventing meaningful statistical comparisons with other firms.

With our definition of HG firms, given the time span available in the data, we end-up with three different measurement of high-growth status for each firm over time. Our last step is to exploit this 3-

\footnotetext{
${ }^{3}$ We discard the first year, 1998, in order to have periods of the same length. The normalization implicitly removes sector-specific common trends, such as inflation and business cycle effects in sectoral demand.
} 
periods panel setting to estimate the following linear probability model that describes the probability to remain in the HG group over time

$$
H G_{i, p}=\alpha+\beta_{0} H G_{i, p-1}+\beta_{1} X_{i, p-1}+\beta_{2} X_{i, p-1} \times H G_{i, p-1}+\text { Controls }_{i, p-1}+\varepsilon_{i, p}
$$

The dependent variable $H G_{i, p}$ is the binary variable indicating if firm $i$ is high-growth in period $p$, and $H G_{i, p-1}$ is the high-growth status of firm $i$ in period $p-1$. The matrix of explanatory variables $X_{i, p-1}$ includes the proxies of structural firm characteristics and performance that we are mostly interested in, lagged by one period, while the matrix Control $_{i, p-1}$ is a set of further firm-level attributes that we consider as controls in the first place, also lagged by one period (see below for the definitions of all the regressors).

The coefficient vector $\beta_{2}$ on the interaction $X_{i, p-1} \times H G_{i, p-1}$ is where our primary interest lies. Indeed, this measures the contribution of each lagged firm attributes in $X_{i, p-1}$ to the probability to be $\mathrm{HG}$ in period $p$ for firms that were already HG in the previous period $p-1$. In this sense, estimates of $\beta_{2}$ allow to address the question whether each focal firm characteristic displays any association with persistence in high-growth status, additional to the association between lagged firm characteristics and the probability to be in the HG group in period $p$ estimated for the "control group" of firms that are not HG firms in period $p-1\left(H G_{p-1}=0\right)$, in turn measured by the coefficient vector $\beta_{1}{ }^{4}$ Notice that the definition of HG is already accounting for more than single-year jumps, so that measuring persistent as being HG over two consecutive periods effectively capture a rather long-run notion of persistence, within the limits imposed by the data. In this we share the idea developed in Bianchini et al. (2017) to go beyond yearly or short-run autocorrelation of HG status or quantile auto-regressions in the top quantiles of the growth rate distribution. They however define a group of persistent high-growth firms fixed over time, and compare their firm-level characteristics with firms that exhibit simple high-growth. The advantage of our framework is that we can track changes in HG status over time, again within the time span allowed by the data.

We test several specifications of Equation (1) where the focal firm attributes in $X_{i, p-1}$ enter one at a time and altogether. Since we are not interested in obtaining fitted probabilities, we estimate all the specifications via OLS. Pooled estimators as the OLS on our linear probability model are consistent without unobserved heterogeneity even in presence of lagged dependent variables. We choose not to include firm fixed-effects essentially because the limited time span available (3 periods) does not allow for that control,

\footnotetext{
${ }^{4}$ The coefficient $\beta_{0}$ measures persistence of $\mathrm{HG}$ status for firms with all firm attributes in $X$ set to zero, and it is as such not particularly informative.
} 
beyond the fact that unobserved heterogeneity is especially troublesome to address in presence of a lagged dependent variable. Omitted heterogeneity and other sources of omitted variables bias, we believe, should be satisfactorily absorbed by the controls, especially when we test a "full model" where all structural characteristics $X_{i, p-1}$ and their corresponding interactions with lagged high-growth status enter at the same time. We will, in fact, consider that specification as the most reliable, as compared to the "univariate" specifications. An issue remains concerning potential standard endogeneity bias, but the short panel does not allow to apply any GMM-like method. In this sense, we do not pretend to identify any causality. We could have defined HG status on yearly basis (top $20 \%$ of growth performance in each year over 19982007) and then estimate a model exploiting the entire 10 years, introducing 1-year or 2-years lags. This would have allowed for methods directly coping with unobserved heterogeneity, and opened up some more flexibility to cure endogeneity via GMM-like estimators or dynamic models for discrete choice, as in LopezGarcia and Puente (2012) that indeed explore whether firm-characteristics impact on a yearly definition of HG (not on persistence of HG, however). Once again, including interactions between past HG status and focal firm attributes would have captured a short-run notion of persistence. ${ }^{5}$

\section{3. $\quad$ Firm characteristics}

In designing our baseline regression model in Equation (1) we distinguish two groups of focal and control firm-level variables.

We derive from theoretical models of firm-industry dynamics the notion that productivity, innovation, profitability, investment behavior, and financial conditions allowing to access external resources represent the key dimensions of firm structural performance underlying growth dynamics. As mentioned, with the exception of Bianchini et al. (2017), these variables are not considered in the few studies addressing persistence of high-growth, while we have more evidence concerning the demographic characteristics (size, age, sector of activity) of persistent high-growth firms. This unbalanced treatment in previous studies, as well as the theoretical relevance of these dimensions, motivates us to include them in the set of focal

\footnotetext{
${ }^{5}$ Another alternative sometimes suggested in the literature on persistence of economic performance (e.g., in innovation studies) would have been to define HG status on a yearly basis, and then employ duration analysis to elicit the influence of focal firm characteristics on the length of the spells of HG growth status, over one, two and more years. However, as expected given the well know erratic nature of growth processes, we verified that in our data about $95 \%$ of all yearly HG events do not last more than 3 years, and actually $65 \%$ of them last just one year. We thank an anonymous referee for suggesting to clarify this point.
} 
characteristics, as potentially distinctive features of high-growth persistence.

The set of focal firm attributes in $X_{p-1}$ includes, thus, the following proxies. We measure productivity as labour productivity, taking the ratio (in logs) of real value added (at constant prices) over number of employees (labeled as PROD). We proxy for operating profitability via the return on sales (ROS), defined as gross operating margins over total output. ${ }^{6}$ We define firm's investment intensity (INV) as the ratio of real investment to real value added, where real investment at time $t$ is the difference of firm's real capital stock between time $t$ and $t-1$, and the time series of real capital stock is computed following Brandt et al. (2012), who apply a standard perpetual inventory method, with a $9 \%$ rate of depreciation. We use the percentage share of output due to new products introduced in each year as our proxy for innovativeness (NEWPROD). ${ }^{7}$ Financial conditions of firms are taken into account through two indicators: a flow measure of the capacity to meet financial obligations in a given year, computed as the ratio between interest expenses and total sales (IE), and a standard measure of leverage (LEV), computed as the ratio between total debt and total assets. ${ }^{8}$

Since all the proxies of focal firm characteristics are continuous variables, in order to input a value for each of the three sub-periods defining the HG status and our regression sample, we take the within-period, firm-specific average of each variable computed over the three years defining each period.

Among the more demographic variables in the control set Controls, we consider age and size of the firms, sector and geographical dummies, as well as two firm-characteristics that may be of particular importance in the context of Chinese industrial development, namely whether a firm is engaged in exporting and whether it is under public (state) or private control.

Firm age (AGE) is computed using information on firm's foundation year, and we proxy for firm size (SIZE) through the $(\log )$ number of employees. As they are both continuous variables, they enter the regression models in terms of their within-period, firm specific averages. Export and state-ownership status are recorded via two binary variables that we construct for each subperiod as follows. We recover

\footnotetext{
${ }^{6}$ Gross margins are essentially equivalent to an EBIDTA index, taking the difference between value added and cost of labour (total wages plus social security).

7 "New products" are defined, according to NBS, as products adopting new technology and/or new design, or products that have been significantly improved over existing ones with respect to their structure, materials and/ or process techniques. Hence, comparing with international standards in innovation surveys as defined by the Oslo manual, "new products" in our data are new to the enterprise, but not necessarily new to the market.

${ }^{8}$ According to Chinese accounting rule, interest expenses is a net measure, which equals gross interest expenses minus interest revenues, and can thus take negative values.
} 


\begin{tabular}{ll} 
Variable name & Definition \\
\hline PROD & (log of) Real value added at constant prices over the number of employees \\
ROS & Gross operating profits over total output \\
INV & Real investment over real value added. \\
NEWPROD & Share of output due to new products \\
LEV & Total debt over total assets \\
AGE & Current year minus foundation year \\
SIZE & (log) Number of employees \\
EXP & Binary variable: 1 if the firm exports in at least one year over the period \\
STATE & Binary variable: 1 if the firm is under state-control in at least two years over the period \\
\hline
\end{tabular}

Table 1: Variables name and definitions. All continuous variables are taken as the average over each of the three-years periods. For the methodology used to computed real investment, see the text.

ownership type from each firm's registration capital, and define a dummy for state-ownership (STATE) that takes value one if the firm is under state-control in at least two years within each three-year subperiod, and zero otherwise. ${ }^{9}$ The export status dummy (EXP) takes value one if the firm exports in at least one year within each three-years subperiod, and zero otherwise. ${ }^{10}$ Controlling for the geographical location of each firm is particularly important, given the well-know disparities in forms and stages of industrial development characterizing the different geographical areas of China. From information in the NBS data, we can include four regional dummies, corresponding to standard macro-division identified in the data: east, middle, west and north east. ${ }^{11}$. All the regressions also include a full set of 2-Digit sectoral dummies, according to the primary sector of activity of each firm. Both regional and sectoral dummies are fixed

\footnotetext{
${ }^{9}$ There are five types of registration capital in the NBS data: state, collective, legal person, individual, Hong-Kong Macao and Taiwan, and foreign. "State-control" indicates both State-absolute-control, i.e., the State capital share is greater than or equal to 50\%, and State-relative-control, i.e., State capital share is less than $50 \%$ but it is greater than the other shareholders or the relative State-controlling status is regulated by the contract.

${ }^{10}$ Notice that export status changes more than ownership and this is the reason why we define the two dummies in two different ways.

${ }^{11}$ More precisely, the East region includes Beijing, Tianjin, Hebei, Shanghai, Jiangsu, Zhejiang, Fujian, Shandong, Guangdong and Hainan. The Middle region includes Shanxi, Anhui, Jiangxi, Henan, Hubei and Hunan. The West region includes Inner Mongolia, Guangxi, Chongqiong, Sichuan, Guizhou, Yunnan, Tibet, Shannxi, Gansu, Qinghai, Ningxia and Xinjiang. The Northeast region includes Liaoning, Jilin and Heilongjiang
} 


\begin{tabular}{|c|c|c|c|c|}
\hline $\mathrm{CIC}$ & Sector & All & HG & $\%$ of $\mathrm{HG}$ \\
\hline 13 & Processing of food from agricultural products & 2830 & 927 & 32.8 \\
\hline 14 & Foodstuff & 1537 & 489 & 31.8 \\
\hline 15 & Manuf. of beverages & 1175 & 365 & 31.1 \\
\hline 16 & Manuf. of tobacco & 150 & 38 & 25.3 \\
\hline 17 & Manuf. of textile & 5061 & 1586 & 31.3 \\
\hline 18 & Manuf. of textile wearing apparel, footwear, cand caps & 3401 & 1160 & 34.1 \\
\hline 19 & Manuf. of leather, fur, feather and related products & 1675 & 506 & 30.2 \\
\hline 20 & Processing of timber, manufacture of wood, bamboo, etc. & 722 & 252 & 34.9 \\
\hline 21 & Manuf. of furniture & 523 & 170 & 32.5 \\
\hline 22 & Manuf. of paper and paper products & 2143 & 650 & 30.3 \\
\hline 23 & Printing, reproduction of recording media & 1677 & 396 & 23.6 \\
\hline 24 & Manuf. of articles for culture, education and sport activity & 1183 & 417 & 35.2 \\
\hline 25 & Processing of petroleum, coking, processing of nuclear fuel & 474 & 145 & 30.6 \\
\hline 26 & Manuf. of raw chemical materials and chemical products & 5602 & 1584 & 28.3 \\
\hline 27 & Manuf. of medicines & 2056 & 576 & 28.0 \\
\hline 28 & Manuf. of chemical fibers & 309 & 122 & 39.5 \\
\hline 29 & Manuf. of rubber & 960 & 305 & 31.8 \\
\hline 30 & Manuf. of plastics & 3112 & 998 & 32.1 \\
\hline 31 & Manuf. of non-metallic mineral products & 6284 & 1882 & 29.9 \\
\hline 32 & Smelting and pressing of ferrous metals & 1128 & 361 & 32.0 \\
\hline 33 & Smelting and pressing of non-ferrous metals & 1004 & 325 & 32.4 \\
\hline 34 & Manuf. of metal products & 3384 & 1061 & 31.4 \\
\hline 35 & Manuf. of general purpose machinery & 5743 & 1716 & 29.9 \\
\hline 36 & Manuf. of special purpose machinery & 2946 & 948 & 32.2 \\
\hline 37 & Manuf. of transport equipment & 3966 & 1226 & 30.9 \\
\hline 39 & Manuf. of electrical machinery and equipment & 4725 & 1563 & 33.1 \\
\hline 40 & Manuf. of communication equipment, computers etc. & 2682 & 948 & 35.3 \\
\hline 41 & Manuf. of measuring instruments and machinery for cultural activity & 1212 & 366 & 30.2 \\
\hline \multirow[t]{2}{*}{42} & Manuf. of artwork and other manufacturing & 1300 & 445 & 34.2 \\
\hline & Total & 68964 & 21527 & 31.2 \\
\hline
\end{tabular}

Table 2: Total number of observations and observations identified as high-growth (absolute number and percentage shares), overall and by 2-digit sectors

over time in the data, thus they equally remain fixed over the three-years period defining our regression analysis. ${ }^{12}$ Table 1 summarizes the name and the definition of all the variables used in the analysis.

\section{Descriptive analysis}

Before turning to regression analysis, we provide a set of preliminary descriptive exercises, offering basic picture about high-growth dynamics and main explanatory variables in the data.

Table 2 shows the total number of observations, the number of HG observations and the percentage share of HG observations in each 2-digit sector, as resulting from our identification criterion, pooling over

\footnotetext{
${ }^{12}$ The data cannot be matched with other data sources, due to confidentiality and restricted access, so we cannot exploit other sources of information to include further region-specific or sector-specific characteristics.
} 


\begin{tabular}{cc|ccc}
\hline & & \multicolumn{3}{|c}{ period +1} \\
& & $H G=0$ & \multicolumn{1}{c}{$H G=1$} & Total \\
\hline \multirow{3}{*}{ period } & $H G=0$ & $22901(72.1 \%)$ & $8860(27.9 \%)$ & $31761(100.0 \%)$ \\
& $H G=1$ & $8636(60.8 \%)$ & $5579(39.2 \%)$ & $14215(100.0 \%)$ \\
& Total & $31537(68.6 \%)$ & $14439(31.4 \%)$ & $45976(100.0 \%)$ \\
\hline
\end{tabular}

Table 3: Transitions in-and-out high-growth status in two consecutive periods: number of observations and transition probabilities in parentheses.

the three sub-periods. Overall, $31 \%$ of observations as belonging to HG firms. Notice that this implies that sales and employment growth are correlated to some extent. Indeed, with our definition, we expect to have from $20 \%$ to $40 \%$ of HG firms in each period, where the lower bound corresponds to perfect crosscorrelation between employment growth and sales growth, whereas the upper bound corresponds to zero correlation between the two growth measures.

Next, Table 3 shows transition probabilities in HG status over two consecutive three-years periods, pooling over the three sub-periods identified in the data. This mimics the type of persistence that we capture in the regression model, not conditional on firm characteristics. We do observe some degree of persistence: around $39 \%$ of the HG firms do not change their status in the next period, whereas firms that are not $\mathrm{HG}$ at time $t$, have around $28 \%$ probability to become HG firms in period $t+1$.

Turning to explanatory variables, Table 4 provides basic descriptive statistics, pooling over the three periods and by HG status within each period. Looking at the overall means (cf. columns labeled as "All"), we detect a clear trend in some of the variables. In particular, the average (log) productivity increased from 3.609 (period 1) to 4.133 (period 2), reflecting the well known productivity growth in Chinese manufacturing over the period. Similarly, we observe a mild increase in the average innovative activity of the firms (the share of output due to new products increased from $4 \%$ to $5.6 \%$ ) and also an increasing share of private or mixed ownership firms (the percentage of State-controlled firms decreases over time from $20 \%$ to about $14 \%$ ). The two financial indicators, IE and LEV, display decreasing patterns, suggesting a general improvement in firms financial conditions. Obviously, the average age of firms increases over time due to the balanced structure of the panel, and also size increases during the period. Also notice that almost half of the firms in our sample are exporters, as we define them, and about 17-20\% are state-owned.

Comparing HG firms with other firms (cf. columns labeled as $H G=1$ vs. $H G=0$ ) reveal other 


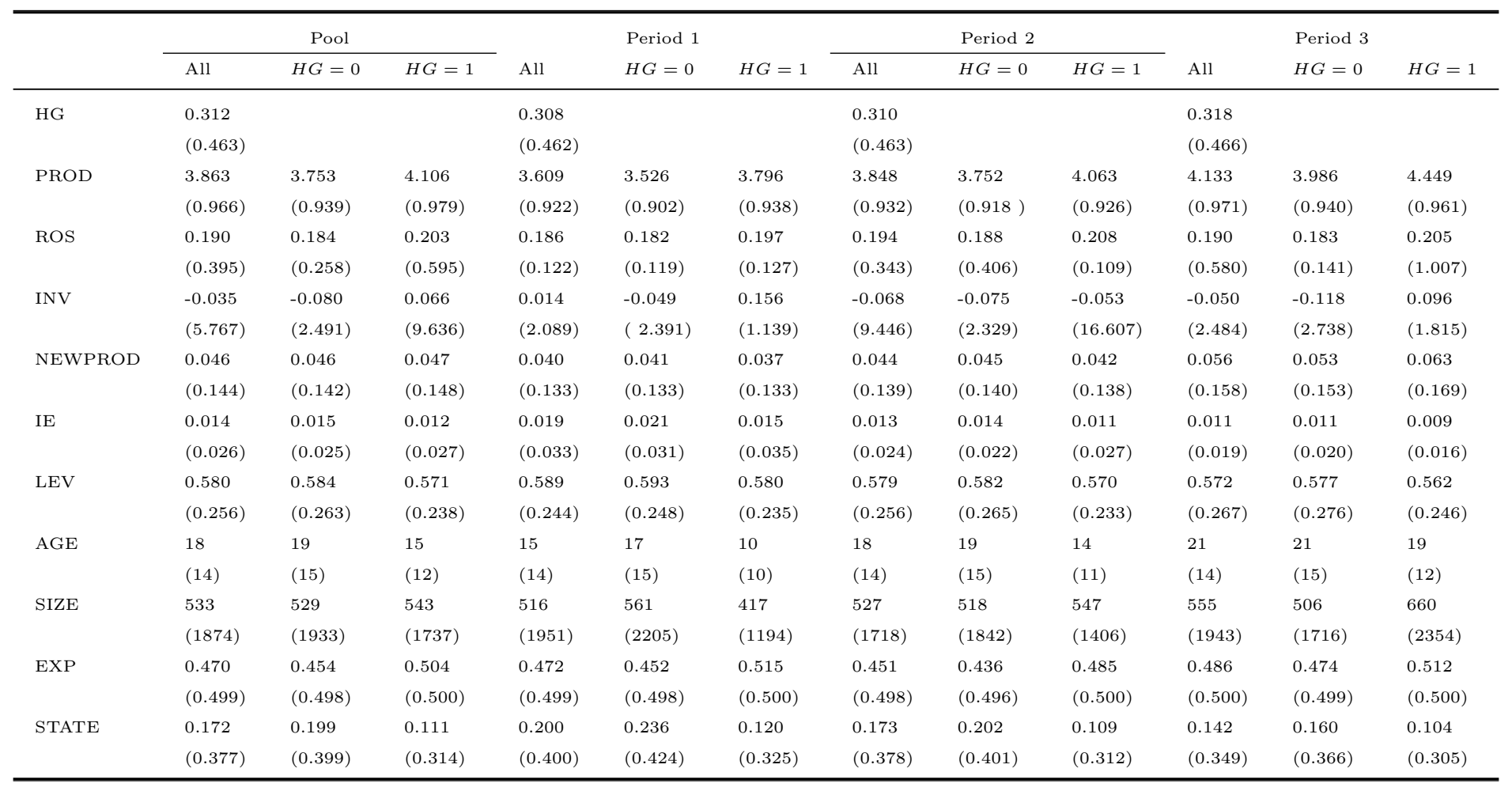

Table 4: Mean and standard deviations (in parenthesis) of the following variables: high-growth status dummy (HG), taking value one if firm is high-growth according to our definition; productivity (PROD) computed as the log of value added over number of employees; return on sales (ROS), computed as gross operating margins over output; investment intensity (INV), computed as real investment over real value added; share of output due to new products (NEWPROD); the ratio of interest expenses to sales (IE); firm leverage (LEV) computed as the ratio of total debt over total assets; number of employees (SIZE); a dummy variable for firms' export status (EXP), taking value one if firm exports; and a dummy variable indicating State-control status (STATE). 
interesting features of the sample. On average, across the three periods, HG firms display higher labour productivity, higher profitability, higher investment intensity, lower interest expenses as a percentage of sales, and lower leverage. HG firms are also younger, but larger in terms of employment (except for period 1). Less marked differences are observed concerning the innovative activity, with the group of other firms performing slightly better in terms of product innovation in period 1 and 2 . Finally, we observe a lower share of State-controlled firms and an higher share of exporters within the HG group. The standard deviations in Table 4 also reveal wide and persistent heterogeneities in all the dimensions of firms' "identity cards", confirming the well known stylised fact that most variables do exhibit high degrees of skewness. ${ }^{13}$ In this sense, average values may not be provide a meaningful reference for comparisons, whereas distributional comparisons are more revealing. Accordingly, we also performed a formal test of distributional equality, for each variable, between the densities estimated for HG and non-HG firms, based on the Fligner and Policello (1981) test.

Table 5 reports the results. We take the group of non-HG firms as the reference category, so that a positive and statistically significant FP statistic indicates that non-HG firms dominates HG firms with respect to the considered firm attribute, while HG firms dominate over other firms when the FP statistic is negative and significant. The tests confirm the conclusion drawn from the comparison of simple averages. In particular, HG firms dominate in terms of productivity, profitability, investment intensity and size, as compared to other firms. Conversely, HG firms do not dominate (i.e. they display lower values, in probability) in terms of interest expenses, leverage and age. Overall, we confirm findings in the literature that high-growth firms tend to display more solid characteristics, beyond being relatively younger, larger, more often exporters and more concentrated in non-State-controlled companies. Results on the share of sales due to product innovation are less clearcut: HG firms tend to outperform other firms only in the last period.

\section{Main results}

High-growth firms appear to differ from other firms. Yet, do firm characteristics stand also out as distinguishing features of high-growth persistence? In this Section we present the main estimates of our baseline regression framework, eliciting the role of our focal firm attributes in the ability to replicate high-growth

\footnotetext{
${ }^{13}$ This is confirmed by looking at kernel densities of all variables, for both HG and other firms. Results not reported, but available upon request.
} 


\begin{tabular}{|c|c|c|c|c|c|c|c|c|c|c|}
\hline \multirow[b]{2}{*}{ Period } & \multicolumn{2}{|c|}{ Number of Obs. } & \multirow[b]{2}{*}{ PROD } & \multirow[b]{2}{*}{ ROS } & \multirow[b]{2}{*}{ INV } & \multirow[b]{2}{*}{ NEWPROD } & \multirow[b]{2}{*}{$\mathrm{IE}$} & \multirow[b]{2}{*}{$\mathrm{LEV}$} & \multirow[b]{2}{*}{ EMP } & \multirow[b]{2}{*}{ AGE } \\
\hline & $H G=0$ & $H G=1$ & & & & & & & & \\
\hline Pool & 47394 & 21570 & $-46.18^{* *}$ & $-25.80 * *$ & $-79.67^{* *}$ & 0.30 & $14.98^{* *}$ & $5.90^{* *}$ & $-4.32^{* *}$ & $42.33^{* *}$ \\
\hline 1999-2001 & 15909 & 7079 & $-21.18^{* *}$ & $-9.88^{* *}$ & $-43.45^{* *}$ & $3.71^{* *}$ & $15.30^{* *}$ & $4.18^{* *}$ & $8.65^{* *}$ & $40.26^{* *}$ \\
\hline $2002-2004$ & 15818 & 7170 & $-24.65^{* *}$ & $-12.01^{* *}$ & $-46.91^{* *}$ & 1.44 & $9.00^{* *}$ & 2.33 & $-5.55^{* *}$ & $25.91^{* *}$ \\
\hline $2005-2007$ & 15667 & 7321 & $-36.78^{* *}$ & $-22.65^{* *}$ & $-49.22^{* *}$ & $-4.37 * *$ & 0.73 & $3.49^{* *}$ & $-10.30 * *$ & $11.68^{* *}$ \\
\hline
\end{tabular}

Table 5: Two-sample Fligner-Policello robust rank order test, both on pooled data and by sub-periods. FP statistics and observations are reported. Non-HG firms as the benchmark group: a positive and significant FP statistic means that non-HG firms dominate; a negative and significant FP statistic means that HG firms dominate. Asterisks denote significance levels $(*: \mathrm{p}<1 \%$; *: $\mathrm{p}<0.1 \%)$.

over time. In the next Section, we will devote specific focus to dissecting the role of age, size and state vs. private ownership.

The results are shown in Table 6. We start presenting the "univariate specifications" where only one firm characteristic and its interaction with lagged HG status are included (see columns 1-6). We find that productivity is associated with an increased probability of high-growth status, and the association is even larger for firms that remain high-growth in two consecutive periods (column 1). Profitability alone does not play an important role in explaining high-growth of non-persistent high-growers, but it is positively associated with the persistence of high-growth (column 2). Firm's product innovation increases the probability that a non-HG firm becomes HG, but there is no additional contribution of product innovation to the persistence of HG firms (column 4). The same holds concerning interest expenses over sales (column 5). Finally we do not detect any statistically significant association between HG status or persistence of HG status for both investment intensity and leverage (columns 3 and 6). Also notice that the coefficients on the control variables are very significant in every specification of the model. Younger and smaller firms tend to have more chances to be high-growth, and the same holds for exporters and firms that are not under direct state-control.

We next move (in column 7) to the estimates of the "full model". The results convey a remarkably different picture, indeed, especially regarding the relevance of firms characteristics to sustain persistence of high-growth. We confirm that lagged productivity and interest expenses (over sales) stand out as key features that distinguish firms that switch from non-HG to HG status over time, while at the same time HG firms suffer from comparatively lower profitability. However, and more interestingly, none of the key 


\begin{tabular}{|c|c|c|c|c|c|c|c|}
\hline Regressors & (1) & (2) & (3) & (4) & $(5)$ & (6) & (7) \\
\hline \multirow[t]{2}{*}{$H G_{p-1}$} & 0.0339 & $0.0568^{* * *}$ & $0.0931^{* * *}$ & $0.0934^{* * *}$ & $0.0959 * * *$ & $0.1069^{* * *}$ & $0.0518^{*}$ \\
\hline & $(0.0202)$ & $(0.0096)$ & $(0.0049)$ & $(0.0051)$ & $(0.0054)$ & $(0.0125)$ & $(0.0257)$ \\
\hline \multirow[t]{2}{*}{$P R O D_{p-1}$} & $0.0326^{* * *}$ & & & & & & $0.0361^{* * *}$ \\
\hline & $(0.0030)$ & & & & & & $(0.0032)$ \\
\hline \multirow[t]{2}{*}{$P R O D_{p-1} \times H G_{p-1}$} & $0.0132^{*}$ & & & & & & 0.0115 \\
\hline & $(0.0052)$ & & & & & & $(0.0061)$ \\
\hline \multirow[t]{2}{*}{$R O S_{p-1}$} & & 0.0022 & & & & & $-0.0193^{* *}$ \\
\hline & & $(0.0183)$ & & & & & $(0.0066)$ \\
\hline \multirow[t]{2}{*}{$R O S_{p-1} \times H G_{p-1}$} & & $0.1785^{* * *}$ & & & & & -0.0047 \\
\hline & & $(0.0415)$ & & & & & $(0.0429)$ \\
\hline \multirow[t]{2}{*}{$I N V_{p-1}$} & & & -0.0012 & & & & -0.0004 \\
\hline & & & $(0.0012)$ & & & & $(0.0013)$ \\
\hline \multirow[t]{2}{*}{$I N V_{p-1} \times H G_{p-1}$} & & & 0.0014 & & & & 0.0006 \\
\hline & & & $(0.0012)$ & & & & $(0.0013)$ \\
\hline \multirow[t]{2}{*}{$N E W P R O D_{p-1}$} & & & & $0.0619^{* *}$ & & & 0.0257 \\
\hline & & & & $(0.0193)$ & & & $(0.0193)$ \\
\hline \multirow[t]{2}{*}{$N E W P R O D_{p-1} \times H G_{p-1}$} & & & & -0.0120 & & & -0.0161 \\
\hline & & & & $(0.0355)$ & & & $(0.0357)$ \\
\hline \multirow[t]{2}{*}{$I E_{p-1}$} & & & & & $0.3228^{* *}$ & & $0.4763^{* * *}$ \\
\hline & & & & & $(0.0999)$ & & $(0.1109)$ \\
\hline \multirow[t]{2}{*}{$I E_{p-1} \times H G_{p-1}$} & & & & & -0.1552 & & -0.1891 \\
\hline & & & & & $(0.1662)$ & & $(0.1859)$ \\
\hline \multirow[t]{2}{*}{$L E V_{p-1}$} & & & & & & -0.0066 & 0.0015 \\
\hline & & & & & & $(0.0098)$ & $(0.0106)$ \\
\hline \multirow[t]{2}{*}{$L E V_{p-1} \times H G_{p-1}$} & & & & & & -0.0238 & -0.0109 \\
\hline & & & & & & $(0.0199)$ & $(0.0209)$ \\
\hline \multirow[t]{2}{*}{$A G E_{p-1}$} & $-0.0017^{* * *}$ & $-0.0020^{* * *}$ & $-0.0021^{* * *}$ & $-0.0021^{* * *}$ & $-0.0021^{* * *}$ & $-0.0020^{* * *}$ & $-0.0018^{* * *}$ \\
\hline & $(0.0002)$ & $(0.0002)$ & $(0.0002)$ & $(0.0002)$ & $(0.0002)$ & $(0.0002)$ & $(0.0002)$ \\
\hline \multirow[t]{2}{*}{$S I Z E_{p-1}$} & $-0.0332^{* * *}$ & $-0.0372^{* * *}$ & $-0.0374^{* * *}$ & $-0.0383^{* * *}$ & $-0.0380^{* * *}$ & $-0.0374^{* * *}$ & $-0.0340^{* * *}$ \\
\hline & $(0.0023)$ & $(0.0023)$ & $(0.0023)$ & $(0.0023)$ & $(0.0023)$ & $(0.0023)$ & $(0.0023)$ \\
\hline \multirow[t]{2}{*}{$E X P_{p-1}$} & $0.0171^{* * *}$ & $0.0214^{* * *}$ & $0.0203^{* * *}$ & $0.0188^{* * *}$ & $0.0210^{* * *}$ & $0.0197^{* * *}$ & $0.0167^{* * *}$ \\
\hline & $(0.0050)$ & $(0.0050)$ & $(0.0050)$ & $(0.0050)$ & $(0.0050)$ & $(0.0050)$ & $(0.0051)$ \\
\hline \multirow[t]{2}{*}{$S T A T E_{p-1}$} & $-0.0512^{* * *}$ & $-0.0516^{* * *}$ & $-0.0521^{* * *}$ & $-0.0542^{* * *}$ & $-0.0534^{* * *}$ & $-0.0518^{* * *}$ & $-0.0543^{* * *}$ \\
\hline & $(0.0059)$ & $(0.0059)$ & $(0.0059)$ & $(0.0060)$ & $(0.0059)$ & $(0.0059)$ & $(0.0059)$ \\
\hline \multirow[t]{2}{*}{ Constant } & $0.3433^{* * *}$ & $0.5041^{* * *}$ & $0.5062^{* * *}$ & $0.5114^{* * *}$ & $0.5055^{* * *}$ & $0.5100^{* * *}$ & $0.3309^{* * *}$ \\
\hline & $(0.0204)$ & $(0.0155)$ & $(0.0150)$ & $(0.0151)$ & $(0.0150)$ & $(0.0160)$ & $(0.0223)$ \\
\hline Observations & 45976 & 45976 & 45976 & 45976 & 45976 & 45976 & 45976 \\
\hline $\mathrm{R} 2$ & 0.0416 & 0.0375 & 0.0369 & 0.0372 & 0.0372 & 0.0370 & 0.0424 \\
\hline
\end{tabular}

Table 6: Linear probability (OLS) estimates of Equation 1. All specifications include 2-digit sectoral dummies and regional dummies. Robust standard errors in parentheses: asterisks denote significance levels (***: p $<0.1 \%$; **: $\mathrm{p}<1 \% ; *: \mathrm{p}<5 \%)$.

structural firm characteristics displays a statistically significant association with the ability to persistently remain in the HG group. Indeed, the estimated interaction coefficients are all statistically equal to zero. 


\section{Dissecting the role of age, size and state-ownership}

The analyses of the previous section suggest that persistently high-growing firms do not seem to differ from "simple" high-growth firms along standard proxies of industrial and structural performance. A major question remains to be answered pertaining to the role of demographic characteristics. A rich stream of literature, starting at least from the seminal work of Birch (1981), has focused in particular on the relationship between size and firm growth. In this perspective, small firms have been considered, especially by policy makers, as the main candidates to become "gazelles". More recent contributions have shown that age, more than size, is the key driver of high-growth performance. In particular, Haltiwanger et al. (2013), using data from the Census Bureau's Longitudinal Business Database (LBD), show that the negative relationship between firm size and growth disappears and may even reverse sign among the biggest firms, once one accounts for the age dimension (see also Lawless (2014) on Irish firms and Grazzi and Moschella (2016) on Italian firms. Decker et al. (2016) provide further evidence on young high growth firms in US). On top of these demographic characteristics, the specific context of the Chinese economy suggests the distinction between state vs. private ownership as a further dimension that can be crucial to identify the origins of extraordinary growth and its persistence.

In this section we explore whether persistence of high-growth itself depends on age, size and ownership type, and we ask if the relations between firm characteristics and persistence of high-growth display specific patterns across firms of different age, size and ownership structure.

\subsection{Young vs. old firms}

Table 7 presents a series of variation of our baseline regression in Equation 1 where we explore the role of firm age. In column 1 we add an explicit interaction between lagged HG status and firm age. Next, we split the sample according to age, defining each firm as young if she is less than 10 years old in the last year of the sample (2007), and as an old firm otherwise. ${ }^{14}$ Young firms account for $3.48 \%$ of total observations, and we exploit this variation in two ways. In column 2 we interact lagged HG status with a dummy identifying young firms, while in columns 3 and 4 we report results of split-sample estimates of Equation 1 by young and old firms.

\footnotetext{
${ }^{14}$ Notice that, given the data span 10 years, young firms include only firms entering the sample exactly during the years covered in the data.
} 


\begin{tabular}{|c|c|c|c|c|}
\hline Regressors & (1) All & (2) All & (3) Old & (4) Young \\
\hline$H G_{p-1}$ & $\begin{array}{l}0.0540^{*} \\
(0.0265)\end{array}$ & $\begin{array}{l}0.0652^{*} \\
(0.0257)\end{array}$ & $\begin{array}{l}0.0658^{*} \\
(0.0263)\end{array}$ & $\begin{array}{l}-0.0341 \\
(0.1314)\end{array}$ \\
\hline$P R O D_{p-1}$ & $\begin{array}{l}0.0362^{* * *} \\
(0.0032)\end{array}$ & $\begin{array}{l}0.0396^{* * *} \\
(0.0032)\end{array}$ & $\begin{array}{l}0.0394^{* * *} \\
(0.0032)\end{array}$ & $\begin{array}{l}0.0466^{*} \\
(0.0227)\end{array}$ \\
\hline$P R O D_{p-1} \times H G_{p-1}$ & $\begin{array}{l}0.0112 \\
(0.0062)\end{array}$ & $\begin{array}{l}0.0096 \\
(0.0061)\end{array}$ & $\begin{array}{l}0.0093 \\
(0.0063)\end{array}$ & $\begin{array}{l}0.0118 \\
(0.0303)\end{array}$ \\
\hline$R O S_{p-1}$ & $\begin{array}{l}-0.0194^{* *} \\
(0.0066)\end{array}$ & $\begin{array}{l}-0.0192^{* *} \\
(0.0068)\end{array}$ & $\begin{array}{l}-0.0191^{* *} \\
(0.0069)\end{array}$ & $\begin{array}{l}-0.0384 \\
(0.1993)\end{array}$ \\
\hline$R O S_{p-1} \times H G_{p-1}$ & $\begin{array}{l}-0.0035 \\
(0.0431)\end{array}$ & $\begin{array}{l}-0.0091 \\
(0.0429)\end{array}$ & $\begin{array}{l}-0.0031 \\
(0.0439)\end{array}$ & $\begin{array}{l}-0.0631 \\
(0.2817)\end{array}$ \\
\hline$I N V_{p-1}$ & $\begin{array}{l}-0.0004 \\
(0.0013)\end{array}$ & $\begin{array}{l}-0.0003 \\
(0.0013)\end{array}$ & $\begin{array}{l}-0.0002 \\
(0.0014)\end{array}$ & $\begin{array}{l}-0.0006 \\
(0.0063)\end{array}$ \\
\hline$I N V_{p-1} \times H G_{p-1}$ & $\begin{array}{l}0.0006 \\
(0.0013)\end{array}$ & $\begin{array}{l}0.0004 \\
(0.0013)\end{array}$ & $\begin{array}{l}0.0004 \\
(0.0014)\end{array}$ & $\begin{array}{l}0.0093 \\
(0.0239)\end{array}$ \\
\hline$N E W P R O D_{p-1}$ & $\begin{array}{l}0.0253 \\
(0.0194)\end{array}$ & $\begin{array}{l}0.0133 \\
(0.0193)\end{array}$ & $\begin{array}{l}0.0141 \\
(0.0196)\end{array}$ & $\begin{array}{l}-0.0645 \\
(0.1237)\end{array}$ \\
\hline$N E W P R O D_{p-1} \times H G_{p-1}$ & $\begin{array}{l}-0.0144 \\
(0.0360)\end{array}$ & $\begin{array}{l}-0.0091 \\
(0.0356)\end{array}$ & $\begin{array}{l}0.0135 \\
(0.0366)\end{array}$ & $\begin{array}{l}-0.3109^{*} \\
(0.1572)\end{array}$ \\
\hline$I E_{p-1}$ & $\begin{array}{l}0.4750^{* * *} \\
(0.1109)\end{array}$ & $\begin{array}{l}0.4766^{* * *} \\
(0.1098)\end{array}$ & $\begin{array}{l}0.4715^{* * *} \\
(0.1108)\end{array}$ & $\begin{array}{l}0.6030 \\
(0.7343)\end{array}$ \\
\hline$I E_{p-1} \times H G_{p-1}$ & $\begin{array}{l}-0.1864 \\
(0.1864)\end{array}$ & $\begin{array}{l}-0.1838 \\
(0.1855)\end{array}$ & $\begin{array}{l}-0.2107 \\
(0.1853)\end{array}$ & $\begin{array}{l}1.2155 \\
(1.2837)\end{array}$ \\
\hline$L E V_{p-1}$ & $\begin{array}{l}0.0013 \\
(0.0106)\end{array}$ & $\begin{array}{l}-0.0087 \\
(0.0105)\end{array}$ & $\begin{array}{l}-0.0061 \\
(0.0106)\end{array}$ & $\begin{array}{l}-0.1321 \\
(0.0778)\end{array}$ \\
\hline$L E V_{p-1} \times H G_{p-1}$ & $\begin{array}{l}-0.0099 \\
(0.0211)\end{array}$ & $\begin{array}{l}-0.0091 \\
(0.0210)\end{array}$ & $\begin{array}{l}-0.0108 \\
(0.0214)\end{array}$ & $\begin{array}{l}0.0911 \\
(0.1132)\end{array}$ \\
\hline$A G E_{p-1}$ & $\begin{array}{l}-0.0018^{* * *} \\
(0.0002)\end{array}$ & & & \\
\hline$A G E_{p-1} \times H G_{p-1}$ & $\begin{array}{l}-0.0001 \\
(0.0004)\end{array}$ & & & \\
\hline$Y O U N G$ & & $\begin{array}{l}0.0423^{* *} \\
(0.0164)\end{array}$ & & \\
\hline$Y O U N G \times H G_{p-1}$ & & $\begin{array}{l}-0.0255 \\
(0.0244)\end{array}$ & & \\
\hline$S I Z E_{p-1}$ & $\begin{array}{l}-0.0340^{* * *} \\
(0.0023)\end{array}$ & $\begin{array}{l}-0.0388^{* * *} \\
(0.0022)\end{array}$ & $\begin{array}{l}-0.0386^{* * *} \\
(0.0023)\end{array}$ & $\begin{array}{l}-0.0408^{* *} \\
(0.0129)\end{array}$ \\
\hline$E X P_{p-1}$ & $\begin{array}{l}0.0166^{* *} \\
(0.0051)\end{array}$ & $\begin{array}{l}0.0205^{* * *} \\
(0.0051)\end{array}$ & $\begin{array}{l}0.0191^{* * *} \\
(0.0051)\end{array}$ & $\begin{array}{l}0.0503 \\
(0.0280)\end{array}$ \\
\hline$S T A T E_{p-1}$ & $\begin{array}{l}-0.0543^{* * *} \\
(0.0059)\end{array}$ & $\begin{array}{l}-0.0720^{* * *} \\
(0.0057)\end{array}$ & $\begin{array}{l}-0.0731^{* * *} \\
(0.0057)\end{array}$ & $\begin{array}{l}-0.0524 \\
(0.0395)\end{array}$ \\
\hline Constant & $\begin{array}{l}0.3303^{* * *} \\
(0.0223)\end{array}$ & $\begin{array}{l}0.3208^{* * *} \\
(0.0223)\end{array}$ & $\begin{array}{l}0.3240^{* * *} \\
(0.0227)\end{array}$ & $\begin{array}{l}0.3371^{* *} \\
(0.1272)\end{array}$ \\
\hline Observations & 45976 & 45976 & 44374 & 1602 \\
\hline $\mathrm{R} 2$ & 0.0424 & 0.0405 & 0.0403 & 0.0628 \\
\hline
\end{tabular}

Table 7: Linear probability (OLS) estimates of Equation 1 adding an interaction of $H G_{p-1}$ with lagged age (column 1) or with a dummy for lagged young firm status (column 2), and split-sample analysis by old and young firms (columns 3 and 4). All specifications include 2-digit sectoral dummies and regional dummies. Robust standard errors in parentheses: asterisks denote significance levels (***: $\mathrm{p}<0.1 \%$; **: $\mathrm{p}<1 \%$; $: \mathrm{p}<5 \%$ ). 
The different specifications convey a consistent picture. On the one hand, we confirm that HG firms tend to be younger than non-HG firms (negative coefficient on AGE and positive on the young-firm dummy), but age does not emerge as a distinguishing feature of persistent high-growth firms, as indeed the interactions of age with lagged HG status are not statistically significant. On the other hand, the coefficient estimated on the other firm attributes broadly replicate the baseline patterns reported in Table 6 . In particular, our focal firm attributes do not display systematic relations with high-growth persistence, neither within young nor within old firms.

\subsection{Small, medium and large firms}

In Table 8 we perform a similar analysis focusing on firm size. We first add an interaction between lagged size (as number of employees) and lagged HG status (in column 1). Next, we explore the relevance of different splits of the sample that identify small vs. medium-large firms, and small-medium vs. large enterprises. We exploit two "official" definitions employed by Chinese authorities: small firms are defined as having less than 300 employees, while small-medium firms are defined as employing less than 1000 employees. ${ }^{15}$ Dummy variables for small and small-medium firms are added, both alone and interacted with lagged HG status in column 2 and column 5, respectively, while split sample analysis by size groups is reported in columns 3-4 (small vs medium-large firms) and in columns 6-7 (small-medium vs. large firms). To avoid simultaneity between growth patterns and the definition of the size groups, we consider the number of employees in the initial year of the sample (1998). Small firms account for $63.75 \%$ of the observations in our balanced panel, while $90.12 \%$ of the sample falls into the small-medium size category.

The results are quite invariant across the different specifications and the different definition of size groups. We confirm our baseline estimates that HG firms are generally smaller in size than other firms, but comparatively smaller size does not play any role in the degree of persistence of high-growth performance, no matter if we take small or small-medium firms as the reference size category. Finally, and much in line with what observed when splitting by age, we once again observe that firm attributes in general do not associate with persistence of high-growth, apart from very small and barely significant coefficients on the size-productivity interaction.

\footnotetext{
${ }^{15}$ This size categorization method was adopted by Chinese State Economic and Trade Commission in 2011.
} 


\begin{tabular}{|c|c|c|c|c|c|c|c|}
\hline Regressors & (1) All & (2) All & $\begin{array}{c}(3) \\
\text { Medium- } \\
\text { Large }\end{array}$ & (4) Small & (5) All & (6) Large & (7) SMEs \\
\hline$H G_{p-1}$ & $\begin{array}{l}0.0399 \\
(0.0395)\end{array}$ & $\begin{array}{l}0.0364 \\
(0.0261)\end{array}$ & $\begin{array}{l}0.0104 \\
(0.0445)\end{array}$ & $\begin{array}{l}0.0692^{*} \\
(0.0325)\end{array}$ & $\begin{array}{l}0.0549 \\
(0.0308)\end{array}$ & $\begin{array}{l}0.1406 \\
(0.0912)\end{array}$ & $\begin{array}{l}0.0385 \\
(0.0271)\end{array}$ \\
\hline$P R O D_{p-1}$ & $\begin{array}{l}0.0360^{* * *} \\
(0.0032)\end{array}$ & $\begin{array}{l}0.0391^{* * *} \\
(0.0032)\end{array}$ & $\begin{array}{l}0.0275^{* * *} \\
(0.0048)\end{array}$ & $\begin{array}{l}0.0508^{* * *} \\
(0.0052)\end{array}$ & $\begin{array}{l}0.0413^{* * *} \\
(0.0032)\end{array}$ & $\begin{array}{l}0.0294^{* * *} \\
(0.0088)\end{array}$ & $\begin{array}{l}0.0443^{* * *} \\
(0.0042)\end{array}$ \\
\hline$P R O D_{p-1} \times H G_{p-1}$ & $\begin{array}{l}0.0120 \\
(0.0063)\end{array}$ & $\begin{array}{l}0.0140 * \\
(0.0062)\end{array}$ & $\begin{array}{l}0.0101 \\
(0.0112)\end{array}$ & $\begin{array}{l}0.0076 \\
(0.0080)\end{array}$ & $\begin{array}{l}0.0136^{*} \\
(0.0061)\end{array}$ & $\begin{array}{l}-0.0080 \\
(0.0224)\end{array}$ & $\begin{array}{l}0.0121 \\
(0.0068)\end{array}$ \\
\hline$R O S$ & $\begin{array}{l}-0.0194^{* *} \\
(0.0066)\end{array}$ & $\begin{array}{l}-0.0196^{* *} \\
(0.0070)\end{array}$ & $\begin{array}{l}-0.0203^{* *} \\
(0.0077)\end{array}$ & $\begin{array}{l}-0.0640 \\
(0.0392)\end{array}$ & $\begin{array}{l}-0.0204^{* *} \\
(0.0072)\end{array}$ & $\begin{array}{l}-0.0193 \\
(0.0120)\end{array}$ & $\begin{array}{l}-0.0475 \\
(0.0300)\end{array}$ \\
\hline$R O S \times H G_{p-1}$ & $\begin{array}{l}-0.0053 \\
(0.0430)\end{array}$ & $\begin{array}{l}-0.0192 \\
(0.0433)\end{array}$ & $\begin{array}{l}0.1055 \\
(0.0766)\end{array}$ & $\begin{array}{l}-0.0293 \\
(0.0628)\end{array}$ & $\begin{array}{l}-0.0208 \\
(0.0434)\end{array}$ & $\begin{array}{l}0.2884 \\
(0.1664)\end{array}$ & $\begin{array}{l}-0.0167 \\
(0.0523)\end{array}$ \\
\hline$I N V_{p-1}$ & $\begin{array}{l}-0.0004 \\
(0.0013)\end{array}$ & $\begin{array}{l}-0.0007 \\
(0.0013)\end{array}$ & $\begin{array}{l}0.0003 \\
(0.0016)\end{array}$ & $\begin{array}{l}-0.0019 \\
(0.0016)\end{array}$ & $\begin{array}{l}-0.0007 \\
(0.0013)\end{array}$ & $\begin{array}{l}0.0002 \\
(0.0026)\end{array}$ & $\begin{array}{l}-0.0016 \\
(0.0014)\end{array}$ \\
\hline$I N V_{p-1} \times H G_{p-1}$ & $\begin{array}{l}0.0006 \\
(0.0013)\end{array}$ & $\begin{array}{l}0.0009 \\
(0.0013)\end{array}$ & $\begin{array}{l}0.0094 \\
(0.0053)\end{array}$ & $\begin{array}{l}0.0020 \\
(0.0016)\end{array}$ & $\begin{array}{l}0.0009 \\
(0.0013)\end{array}$ & $\begin{array}{l}0.0066 \\
(0.0039)\end{array}$ & $\begin{array}{l}0.0017 \\
(0.0014)\end{array}$ \\
\hline$N E W P R O D_{p-1}$ & $\begin{array}{l}0.0266 \\
(0.0194)\end{array}$ & $\begin{array}{l}0.0069 \\
(0.0193)\end{array}$ & $\begin{array}{l}-0.0084 \\
(0.0247)\end{array}$ & $\begin{array}{l}0.0373 \\
(0.0316)\end{array}$ & $\begin{array}{l}0.0035 \\
(0.0194)\end{array}$ & $\begin{array}{l}0.0350 \\
(0.0397)\end{array}$ & $\begin{array}{l}-0.0079 \\
(0.0226)\end{array}$ \\
\hline$N E W P R O D_{p-1} \times H G_{p-1}$ & $\begin{array}{l}-0.0187 \\
(0.0363)\end{array}$ & $\begin{array}{l}-0.0128 \\
(0.0361)\end{array}$ & $\begin{array}{l}0.0061 \\
(0.0542)\end{array}$ & $\begin{array}{l}-0.0402 \\
(0.0507)\end{array}$ & $\begin{array}{l}-0.0162 \\
(0.0362)\end{array}$ & $\begin{array}{l}-0.0154 \\
(0.0875)\end{array}$ & $\begin{array}{l}-0.0105 \\
(0.0403)\end{array}$ \\
\hline$I E_{p-1}$ & $\begin{array}{l}0.4778^{* * *} \\
(0.1110)\end{array}$ & $\begin{array}{l}0.4456^{* * *} \\
(0.1112)\end{array}$ & $\begin{array}{l}0.4935^{* *} \\
(0.1546)\end{array}$ & $\begin{array}{l}0.3814^{*} \\
(0.1628)\end{array}$ & $\begin{array}{l}0.4132^{* * *} \\
(0.1101)\end{array}$ & $\begin{array}{l}0.3056 \\
(0.2379)\end{array}$ & $\begin{array}{l}0.4299^{* * *} \\
(0.1197)\end{array}$ \\
\hline$I E_{p-1} \times H G_{p-1}$ & $\begin{array}{l}-0.1905 \\
(0.1859)\end{array}$ & $\begin{array}{l}-0.1478 \\
(0.1854)\end{array}$ & $\begin{array}{l}-0.3314 \\
(0.3553)\end{array}$ & $\begin{array}{l}-0.0560 \\
(0.2341)\end{array}$ & $\begin{array}{l}-0.1232 \\
(0.1845)\end{array}$ & $\begin{array}{l}0.6768 \\
(0.7740)\end{array}$ & $\begin{array}{l}-0.1615 \\
(0.1923)\end{array}$ \\
\hline$L E V_{p-1}$ & $\begin{array}{l}0.0014 \\
(0.0106)\end{array}$ & $\begin{array}{l}0.0045 \\
(0.0106)\end{array}$ & $\begin{array}{l}-0.0101 \\
(0.0163)\end{array}$ & $\begin{array}{l}0.0143 \\
(0.0138)\end{array}$ & $\begin{array}{l}0.0055 \\
(0.0106)\end{array}$ & $\begin{array}{l}0.0285 \\
(0.0304)\end{array}$ & $\begin{array}{l}0.0028 \\
(0.0113)\end{array}$ \\
\hline$L E V_{p-1} \times H G_{p-1}$ & $\begin{array}{l}-0.0108 \\
(0.0209)\end{array}$ & $\begin{array}{l}-0.0110 \\
(0.0210)\end{array}$ & $\begin{array}{l}0.0259 \\
(0.0385)\end{array}$ & $\begin{array}{l}-0.0286 \\
(0.0252)\end{array}$ & $\begin{array}{l}-0.0127 \\
(0.0209)\end{array}$ & $\begin{array}{l}-0.1218 \\
(0.0812)\end{array}$ & $\begin{array}{l}-0.0045 \\
(0.0218)\end{array}$ \\
\hline$S I Z E_{p-1}$ & $\begin{array}{l}-0.0346^{* * *} \\
(0.0026)\end{array}$ & & & & & & \\
\hline$S I Z E_{p-1} \times H G_{p-1}$ & $\begin{array}{l}0.0019 \\
(0.0046)\end{array}$ & & & & & & \\
\hline$S M A L L$ & & $\begin{array}{l}0.0457^{* * *} \\
(0.0056)\end{array}$ & & & & & \\
\hline$S M A L L \times H G_{p-1}$ & & $\begin{array}{l}-0.0004 \\
(0.0106)\end{array}$ & & & & & \\
\hline$S M E s$ & & & & & $\begin{array}{l}0.0332^{* * *} \\
(0.0079)\end{array}$ & & \\
\hline$S M E s \times H G_{P-1}$ & & & & & $\begin{array}{l}-0.0145 \\
(0.0185)\end{array}$ & & \\
\hline$A G E_{p-1}$ & $\begin{array}{l}-0.0018^{* * *} \\
(0.0002)\end{array}$ & $\begin{array}{l}-0.0020^{* * *} \\
(0.0002)\end{array}$ & $\begin{array}{l}-0.0016^{* * *} \\
(0.0002)\end{array}$ & $\begin{array}{l}-0.0025^{* * *} \\
(0.0003)\end{array}$ & $\begin{array}{l}-0.0023^{* * *} \\
(0.0002)\end{array}$ & $\begin{array}{l}-0.0010^{* *} \\
(0.0004)\end{array}$ & $\begin{array}{l}-0.0027^{* * *} \\
(0.0002)\end{array}$ \\
\hline$E X P_{p-1}$ & $\begin{array}{l}0.0167^{* * *} \\
(0.0051)\end{array}$ & $\begin{array}{l}0.0035 \\
(0.0049)\end{array}$ & $\begin{array}{l}-0.0044 \\
(0.0079)\end{array}$ & $\begin{array}{l}0.0060 \\
(0.0063)\end{array}$ & $\begin{array}{l}-0.0018 \\
(0.0049)\end{array}$ & $\begin{array}{l}-0.0105 \\
(0.0148)\end{array}$ & $\begin{array}{l}-0.0026 \\
(0.0052)\end{array}$ \\
\hline$S T A T E_{p-1}$ & $\begin{array}{l}-0.0541^{* * *} \\
(0.0060)\end{array}$ & $\begin{array}{l}-0.0607^{* * *} \\
(0.0059)\end{array}$ & $\begin{array}{l}-0.0731^{* * *} \\
(0.0082)\end{array}$ & $\begin{array}{l}-0.0523^{* * *} \\
(0.0088)\end{array}$ & $\begin{array}{l}-0.0637^{* * *} \\
(0.0060)\end{array}$ & $\begin{array}{l}-0.0585^{* * *} \\
(0.0162)\end{array}$ & $\begin{array}{l}-0.0669^{* * *} \\
(0.0065)\end{array}$ \\
\hline Constant & $\begin{array}{l}0.3345^{* * *} \\
(0.0236)\end{array}$ & $\begin{array}{l}0.1260^{* * *} \\
(0.0195)\end{array}$ & $\begin{array}{l}0.1963^{* * *} \\
(0.0305)\end{array}$ & $\begin{array}{l}0.1227^{* * *} \\
(0.0256)\end{array}$ & $\begin{array}{l}0.1257^{* * *} \\
(0.0209)\end{array}$ & $\begin{array}{l}0.1512^{*} \\
(0.0629)\end{array}$ & $\begin{array}{l}0.1589^{* * *} \\
(0.0207)\end{array}$ \\
\hline Observations & 45976 & 45976 & 16668 & 29308 & 45976 & 4542 & 41434 \\
\hline $\mathrm{R} 2$ & 0.0424 & 0.0395 & 0.0352 & 0.0310 & 0.0380 & 0.0413 & 0.0356 \\
\hline
\end{tabular}

Table 8: Linear probability (OLS) estimates of Equation 1 exploring the role of firm size (as number of employees): in column 1 we add an interaction $S I Z E_{p-1} \times H G_{p-1}$; in column 2 we add an interaction between $H G_{p-1}$ and a dummy for lagged small firm status (less than 300 employees); in column 3 and 4 we split the sample between small vs medium-large (more than 300 employees) firms; in column 5 we add an interaction between $H G_{p-1}$ and lagged small-medium firm status (less than 1000 employees); in column 6 and 7 we split the sample between small-medium vs large (more than 1000 employees) firms. All specifications include 2-digit sectoral dummies and regional dummies. Robust standard errors in parentheses: astę6s denote significance levels $\left(* * *: \mathrm{p}<0.1 \% ;{ }^{* *}: \mathrm{p}<1 \% ; *\right.$ : $<<5 \%$ ). 


\subsection{State-controlled vs. non-state-controlled firms}

Finally, in Table 9 we explore whether there is a relation between high-growth persistence and state ownership. In column 1 we simply add an interaction between the (lagged) dummy STATE with (lagged) HG status. Next, in columns 2 and 3, we report split-sample estimates of the baseline regression model performed separately in the two groups of state-controlled vs. non-state-controlled firms.

Two remarkable results emerge. First, we find that non-state-controlled firms are more likely to become HG, but ownership type does not affect persistence of HG status (see column 1). Second, we still obtain that structural characteristics do not show systematic predictive power for the ability to replicate high-growth events over time. Productivity is the only variable that does, although only in one single specification (see the interaction coefficient in column 3).

\section{Final remarks}

While a large literature studies the characteristics of high-growth firms, and the conditions that can ease their birth and development, in this paper we ask the perhaps more crucial question concerning the characteristics that are associated with the ability to achieve high-growth persistently over time. From a policy perspective, persistent high-growth firms turn more attractive than "simple" high-growers, since more substantive and long-lasting gains for the economy are plausibly to be expected from firms that consistently outperform over time.

Notwithstanding its relevance, persistence of high-growth receives little and only very recent attention in the empirical literature. From the few existing studies, mostly based on developed countries, we know that persistently high-growing firms represent a small subset of the industrial sector and are usually smaller in size and younger. The dynamism of the Chinese economy during the miracle of the 2000s, sustained by the Chinese authorities through promotion of entrepreneurship and private business, provides an interesting test to the identification of the characteristics that distinguish persistently high-growth firms.

Our main finding, however, is that structural characteristics do not display any systematic association with the probability to replicate high-growth over time. The result challenges most theories of firm-industry dynamics sharing the notion that idiosyncratic specificities of firms are the key drivers of comparative advantages leading to sustained growth over time. Rather, our findings may be interpreted as more in line with theories that conceptualize high-growth as a random process essentially guided by luck. 


\begin{tabular}{|c|c|c|c|}
\hline Regressors & (1) All & $\begin{array}{c}(2) \\
\text { Non-State-control } \\
\end{array}$ & $\begin{array}{c}(3) \\
\text { State-control }\end{array}$ \\
\hline \multirow[t]{2}{*}{$H G_{p-1}$} & $0.0552^{*}$ & $0.0727^{* *}$ & -0.0646 \\
\hline & $(0.0258)$ & $(0.0280)$ & $(0.0687)$ \\
\hline \multirow[t]{2}{*}{$P R O D_{p-1}$} & $0.0365^{* * *}$ & $0.0407^{* * *}$ & $0.0218^{* *}$ \\
\hline & $(0.0032)$ & $(0.0045)$ & $(0.0069)$ \\
\hline \multirow[t]{2}{*}{$P R O D_{p-1} \times H G_{p-1}$} & 0.0111 & 0.0040 & $0.0411^{* *}$ \\
\hline & $(0.0061)$ & $(0.0071)$ & $(0.0154)$ \\
\hline \multirow[t]{2}{*}{$R O S_{p-1}$} & $-0.0198^{* *}$ & -0.0270 & -0.0049 \\
\hline & $(0.0067)$ & $(0.0344)$ & $(0.0065)$ \\
\hline \multirow{2}{*}{$R O S_{p-1} \times H G_{p-1}$} & -0.0043 & 0.0235 & -0.0956 \\
\hline & $(0.0431)$ & $(0.0574)$ & $(0.0824)$ \\
\hline \multirow[t]{2}{*}{$I N V_{p-1}$} & -0.0003 & 0.0021 & $-0.0029^{*}$ \\
\hline & $(0.0013)$ & $(0.0015)$ & $(0.0014)$ \\
\hline \multirow[t]{2}{*}{$I N V_{p-1} \times H G_{p-1}$} & 0.0005 & -0.0019 & 0.0157 \\
\hline & $(0.0013)$ & $(0.0015)$ & $(0.0081)$ \\
\hline \multirow[t]{2}{*}{$N E W P R O D_{p-1}$} & 0.0222 & 0.0111 & $0.0648^{*}$ \\
\hline & $(0.0194)$ & $(0.0245)$ & $(0.0327)$ \\
\hline \multirow[t]{2}{*}{$N E W P R O D_{p-1} \times H G_{p-1}$} & -0.0075 & 0.0172 & -0.0872 \\
\hline & $(0.0361)$ & $(0.0427)$ & $(0.0693)$ \\
\hline \multirow[t]{2}{*}{$I E_{p-1}$} & $0.4573^{* * *}$ & $0.5061^{* * *}$ & 0.3114 \\
\hline & $(0.1104)$ & $(0.1316)$ & $(0.1784)$ \\
\hline \multirow[t]{2}{*}{$I E_{p-1} \times H G_{p-1}$} & -0.1548 & -0.2365 & 0.0794 \\
\hline & $(0.1876)$ & $(0.2188)$ & $(0.2840)$ \\
\hline \multirow[t]{2}{*}{$L E V_{p-1}$} & 0.0002 & -0.0038 & 0.0224 \\
\hline & $(0.0106)$ & $(0.0121)$ & $(0.0216)$ \\
\hline \multirow[t]{2}{*}{$L E V_{p-1} \times H G_{p-1}$} & -0.0105 & -0.0070 & -0.0002 \\
\hline & $(0.0209)$ & $(0.0229)$ & $(0.0539)$ \\
\hline \multirow[t]{2}{*}{$S T A T E_{p-1}$} & $-0.0480^{* * *}$ & & \\
\hline & $(0.0066)$ & & \\
\hline \multirow[t]{2}{*}{$S T A T E_{p-1} \times H G_{p-1}$} & -0.0278 & & \\
\hline & $(0.0146)$ & & \\
\hline \multirow[t]{2}{*}{$A G E_{p-1}$} & $-0.0019^{* * *}$ & $-0.0024^{* * *}$ & $-0.0009^{* * *}$ \\
\hline & $(0.0002)$ & $(0.0002)$ & $(0.0003)$ \\
\hline \multirow[t]{2}{*}{$S I Z E_{p-1}$} & $-0.0343^{* * *}$ & $-0.0355^{* * *}$ & $-0.0334^{* * *}$ \\
\hline & $(0.0023)$ & $(0.0027)$ & $(0.0048)$ \\
\hline \multirow[t]{2}{*}{$E X P_{p-1}$} & $0.0170^{* * *}$ & $0.0162^{* *}$ & 0.0071 \\
\hline & $(0.0051)$ & $(0.0056)$ & $(0.0117)$ \\
\hline \multirow[t]{2}{*}{ Constant } & $0.3295^{* * *}$ & $0.3208^{* * *}$ & $0.3444^{* * *}$ \\
\hline & $(0.0223)$ & $(0.0263)$ & $(0.0466)$ \\
\hline Observations & 45976 & 38736 & 7240 \\
\hline $\mathrm{R} 2$ & 0.0423 & 0.0344 & 0.0440 \\
\hline
\end{tabular}

Table 9: Linear probability (OLS) estimates of Equation 1 adding an interaction of $H G_{p-1}$ with a dummy of lagged state-control status (column 1), and split-sample analysis by non-State-control and State-control firms (columns 2 and 3). All specifications include 2-digit sectoral dummies and regional dummies. Robust standard errors in parentheses: asterisks denote significance levels $(* * *: \mathrm{p}<0.1 \% ; * *: \mathrm{p}<1 \% ; *: \mathrm{p}<5 \%)$. 
The implications of our findings are perhaps not good news for policy makers. Our analysis indeed speaks against too simplistic views on the large benefits usually attributed to the emergence and development of high-growth firms. Since those few firms that display a systematic ability to persistently achieve high-growth do not differ from other firms along any of the dimension of industrial and financial performance considered, it is not to be expected that they contribute to improving the overall performance of the economy over the medium-long run. As such, our results suggest that policy measures sustaining highgrowth firms may be doomed to only exert short-term effects on the economy. In this respect, the findings are surprising, since the spectacular growth achieved in China during the period under study would have suggested that, first, more firms were able to achieve persistent high-growth, and, second, that such firms were indeed bringing positive contribution to the economy, especially in terms of efficiency, profits and balanced financial structures. Conversely, we essentially replicate the conclusions drawn by Bianchini et al. (2017) from their analysis of European firms. This similarity of findings across countries suggests that our results may not be peculiar to the Chinese context, and perhaps the initial emergence of a stylised empirical regularity that something more than more than structural characteristics drives sustained high-growth over time, independently from country and time.

Needless to say, further analysis is needed to further corroborate our conclusions. This work only provides strong evidence that there are no statistically significant differences across persistent high-growth and other firms, whereas we do not claim any causal interpretation. Relatedly, a promising avenue for further research would be to undertake systematic analysis of long-run high-growth performance of firms receiving policy support, while we cannot conduct a direct policy evaluation exercise in this study. Moreover, beyond the obvious need to validate our results on other countries, institutional contexts and time periods, an interesting extension of the analysis would be to include factors of more direct derivation from management research, for which we do not have data, e.g. looking deeper into capabilities, organizational characteristics, firm strategies and managerial or entrepreneurial characteristics. At the same time, although we stress the need to consider a long-run notion of high-growth persistence, beyond the usual focus on single-year or very short-run spurts of high-growth, the understanding of persistent high-growth dynamics would greatly benefit from the availability of longer-in-time datasets. 


\section{References}

ACs, Z. ANd P. Mueller (2008): "Employment effects of business dynamics: Mice, Gazelles and Elephants," Small Business Economics, 30, 85-100.

Acs, Z., J. Parsons, And W. Tracy (2011): "High-impact firms: Gazelles revisited," in Handbook of research on entrepreneurship and regional development: National and regional perspectives, ed. by M. Fritsch, Cheltenham: Edward Elgar Publishing, 133-174.

Audretsch, D. B., A. Coad, And A. Segarra (2014): "Firm growth and innovation," Small business economics, $43,743-749$.

BARNEY, J. B. (1997): "On flipping coins and making technology choices: Luck as an explanation of technological foresight and oversight," in Technological Innovation: Oversights and Foresights, ed. by R. Garud, P. R. Nayyar, and Z. B. Shapira, Cambridge University Press: Cambridge, UK.

Baumol, W. J. (1990): "Entrepreneurship: Productive, Unproductive, and Destructive," Journal of Political Economy, 98, 893-921.

(2010): The Microtheory of Innovative Entrepreneurship, no. 9216 in Economics Books, Princeton University Press.

Beck, T., A. Demirgü̧̧-Kunt, And V. Maksimovic (2005): "Financial and legal constraints to growth: Does firm size matter?" The Journal of Finance, 60, 137-177.

Bellak, C. (2004): "How domestic and foreign firms differ and why does it matter?" Journal of economic surveys, $18,483-514$.

Bianchini, S., G. Bottazzi, And F. TAmagni (2017): "What does (not) characterize persistent corporate highgrowth?" Small Business Economics, 48, 633-656.

Bianchini, S., G. Pellegrino, and F. Tamagni (2016): "Innovation Strategies and Firm Growth," LEM Working Papers 2016/03, Laboratory of Economics and Management (LEM), Sant'Anna School of Advanced Studies, Pisa, Italy.

BIRCH, D. L. (1981): "Who creates jobs," Public Interest, 65, 3-14.

Birch, D. L. And J. Medoff (1994): "Gazelles," in Labor markets, employment policy and job creation, ed. by C. S. Lewis and R. L. Alec, Boulder: Westview Press, 159-167. 
Bottazzi, G., G. Dosi, And G. Rocchetti (2001): "Modes of Knowledge Accumulation, Entry Regimes and Patterns of Industrial Evolution," Industrial and Corporate Change, 10, 609-38.

Bottazzi, G., A. Secchi, and F. Tamagni (2014): "Financial constraints and firm dynamics," Small Business Economics, 42, 99-116.

Brandt, L., J. Van Biesebroeck, And Y. Zhang (2012): "Creative accounting or creative destruction? Firmlevel productivity growth in Chinese manufacturing," Journal of Development Economic, 97, 339-351.

Capasso, M., E. Cefis, and K. Frenken (2014): "On the existence of persistently outperforming firms," Industrial and Corporate Change, 23, 997-1036.

Chang, W. And I. C. MacMillan (1991): "A review of entrepreneurial development in the People's Republic of China," Journal of Business Venturing, 6, 375-379.

Clementi, G. L. And H. A. Hopenhayn (2006): "A theory of financing constraints and firm dynamics," The Quarterly Journal of Economics, 121, 229-265.

CoAD, A. (2007): "A closer look at serial growth rate correlation," Review of Industrial Organization, 31, 69-82.

Coad, A., S.-O. Daunfeldt, W. Hölzl, D. Johansson, and P. Nightingale (2014): "High-growth firms: introduction to the special section," Industrial and Corporate Change, 23, 91-112.

CoAD, A. AND W. Hölzl (2009): "On the autocorrelation of growth rates," Journal of Industry, Competition and Trade, 9, 139-166.

CoAD, A. AND W. HölzL (2012): "Firm Growth: Empirical Analysis," in Handbook on the Economics and Theory of the Firm, Cheltenham, UK: Edward Elgar Publishing, Inc.

COAD, A. AND R. RAO (2008): "Innovation and firm growth in high-tech sectors: A quantile regression approach," Research policy, 37, 633-648.

CoAD, A., R. RaO, And F. TAmagni (2011): "Growth processes of Italian manufacturing firms," Structural Change and Economic Dynamics, 22, 54-70.

Coad, A., A. Segarra, And M. Teruel (2016): "Innovation and firm growth: Does firm age play a role?" Research Policy, 45, 387-400.

Covin, J. G., K. M. Green, And D. P. Slevin (2006): "Strategic process effects on the entrepreneurial orientation-sales growth rate relationship," Entrepreneurship theory and practice, 30, 57-81. 
Daunfeldt, S.-O., N. Elert, And D. Johansson (2010): "The economic contribution of high-growth firms: Do definitions matter?" Stockholm: The Ratio Institute.

(2014): "The economic contribution of high-growth firms: do policy implications depend on the choice of growth indicator?" Journal of Industry, Competition and Trade, 14, 337-365.

Daunfeldt, S.-O. And D. Halvarsson (2015): "Are high-growth firms one-hit wonders? Evidence from Sweden," Small Business Economics, 44, 361-383.

Davidsson, P. And M. Henrekson (2002): "Determinants of the Prevalence of Start-Ups and High-Growth Firms," Small Business Economics, 19, 81-104.

Decker, R. A., J. Haltiwanger, R. S. Jarmin, And J. Miranda (2016): "Where has all the skewness gone? The decline in high-growth (young) firms in the U.S." European Economic Review, 86, $4-23$.

Delmar, F., P. Davidsson, And W. B. Gartner (2003): "Arriving at the high-growth firm," Journal of Business Venturing, 18, 189-216.

Dosi, G., O. Marsili, L. Orsenigo, And R. Salvatore (1995): "Learning, Market Selection and Evolution of Industrial Structures," Small Business Economics, 7, 411-36.

Dosi, G., R. Nelson, AND S. Winter (2001): The nature and dynamics of organizational capabilities, OUP Oxford.

Dosi, G. ET AL. (2007): "Statistical Regularities in the Evolution of Industries. A Guide through some Evidence and Challenges for the Theory," Perspectives on innovation, 1110-1121.

Du, J. And Y. Temouri (2015): "High-growth firms and productivity: evidence from the United Kingdom," Small business economics, 44, 123-143.

ERICson, R. AND A. PAKes (1995): "Markov-Perfect Industry Dynamics: A Framework for Empirical Work," Review of Economic Studies, 62, 53-82.

Fligner, M. A. And G. E. Policello (1981): "Robust rank procedures for the Behrens-Fisher problem," Journal of the American Statistical Association, 76, 162-168.

Fu, X. AND Y. Gong (2011): "Indigenous and Foreign Innovation Efforts and Drivers of Technological Upgrading: Evidence from China," World Development, 39, 1213-1225.

GarsaA, A. And N. Levratto (2015): "Do labor tax rebates facilitate firm growth? An empirical study on French establishments in the manufacturing industry, 2004-2011," Small Business Economics, 45, 613-641. 
Goedhuys, M. And L. Sleuwaegen (2010): "High-growth entrepreneurial firms in Africa: a quantile regression approach," Small Business Economics, 34, 31-51.

Grazzi, M. and D. Moschella (2016): "Small, young, and exporters: New evidence on the determinants of firm growth," LEM Working Papers 2016/07, Sant'Anna School of Advanced Studies, Pisa, Italy.

Guarascio, D. And F. TAmagni (2016): "Persistence of Innovation and Patterns of Firm Growth," LEM Working Papers 2016/31, Sant'Anna School of Advanced Studies, Pisa, Italy.

Guariglia, A., X. Liu, And L. Song (2011): "Internal finance and growth: Microeconometric evidence on Chinese firms," Journal of Development Economics, 96, 79-94.

Haltiwanger, J., R. S. Jarmin, And J. Miranda (2013): "Who Creates Jobs? Small versus Large versus Young," The Review of Economics and Statistics, 95, 347-361.

Henrekson, M. And D. Johansson (2010): "Gazelles as job creators: a survey and interpretation of the evidence," Small Business Economics, 35, 227-244.

Hobday, M. And F. A. D. B. Perini (2009): "Latecomer entrepreneurship: a policy perspective," in Industrial Policy and Development: the political economy of capabilities accumulation, ed. by M. Cimoli, G. Dosi, and J. E. Stiglitz, Oxford University Press.

HöLzL, W. (2009): "Is the R\&D behaviour of fast-growing SMEs different? Evidence from CIS III data for 16 countries," Small Business Economics, 33, 59-75.

- (2014): "Persistence, survival, and growth: a closer look at 20 years of fast-growing firms in Austria," Industrial and corporate change, 23, 199-231.

Hopenhayn, H. A. (1992): "Entry, Exit, and Firm Dynamics in Long Run Equilibrium," Econometrica, 60, 1127-50.

Hu, A. G. Z., G. H. Jefferson, And J. Qian (2005): "R\&D and Technology Transfer: Firm-Level Evidence from Chinese Industry," The Review of Economics and Statistics, 87, 780-786.

Huang, Y. (2010): "Entrepreneurship in China," The World Financial Review.

Huergo, E. And J. Jaumandreu (2004): "Firms' age, process innovation and productivity growth," International Journal of Industrial Organization, 22, 541-559.

Jovanovic, B. (1982): "Selection and the Evolution of Industry," Econometrica, 50, 649-70.

Krasniqi, B. A. And S. Desai (2016): "Institutional drivers of high-growth firms: country-level evidence from 26 transition economies," Small Business Economics, 47, 1075-1094. 
LaWless, M. (2014): "Age or Size? Contributions to job creation," Small Business Economics, 42, 815-830.

LI, H. (2013): "History and development of entrepreneurship in China," in Entrepreneurship and Economic Growth in China, ed. by T. Zhang and R. R. Stough, World Scientific, 13-33.

Li, J. AND H. Matlay (2006): "Chinese entrepreneurship and small business development: an overview and research agenda," Journal of Small Business and Enterprise Development, 13, 248-262.

Lopez-Garcia, P. And S. Puente (2012): "What makes a high-growth firm? A dynamic probit analysis using Spanish firm-level data," Small Business Economics, 39, 1029-1041.

Luttmer, E. G. J. (2007): "Selection, growth and the size distribution of firms," The Quarterly Journal of Economics, 122, 1103-1144.

Metcalfe, S. J. (1998): Evolutionary Economics and Creative Destruction, London, UK: Routledge.

Nelson, R. R. And S. G. Winter (1982): An Evolutionary Theory of Economic Change, Harvard University Press.

Oliveira, B. And A. Fortunato (2006): "Firm Growth and Liquidity Constraints: A Dynamic Analysis," Small Business Economics, 27, 139-156.

Pisano, G. P. (2015): "A Normative Theory of Dynamic Capabilities: Connecting Strategy, Know-How, and Competition," Harvard Business School Technology Eamp; Operations Mgt. Unit Working Paper.

Robson, P. J. And R. J. Bennett (2000): "SME growth: The relationship with business advice and external collaboration," Small business economics, 15, 193-208.

SANTi, C. AND P. SANTOLERI (2016): "Exploring the link between Innovation and Growth in Chilean firms," LEM Working Papers 2016/09, Laboratory of Economics and Management (LEM), Sant'Anna School of Advanced Studies, Pisa, Italy.

Schreyer, P. (2000): "High-growth firms and employment," Science, Technology and Industry Working Paper series: 2000/03, OECD Publishing.

Segarra, A. And M. Teruel (2014): "High-growth firms and innovation: an empirical analysis for Spanish firms," Small Business Economics, 43, 805-821.

Stam, E. And K. Wennberg (2009): "The roles of R\&D in new firm growth," Small Business Economics, 33, $77-89$. 
Teece, D. And G. Pisano (1994): "The dynamic capabilities of firms: an introduction," Industrial and corporate change, $3,537-556$.

Teece, D. J., G. Pisano, And A. Shuen (1997): "Dynamic capabilities and strategic management," Strategic management journal, 509-533.

Winter, S. G. (1984): "Schumpeterian competition under alternative technological regimes," Journal of Economic Behavior and Organization, 5, 287-320.

YANG, J. Y. AND J. Li (2008): "The development of entrepreneurship in China," Asia Pacific Journal of Management, 25, 335-359.

Yu, X., G. Dosi, M. Grazzi, And J. Lei (2015a): "Inside the Virtuous Cycle between Productivity, Profitability, Investment and Corporate Growth: An Anatomy of China Industrialization," LEM Working Paper Series 2015/03.

Yu, X., G. Dosi, J. Lei, ANd A. Nuvolari (2015b): "Institutional change and productivity growth in China's manufacturing: the microeconomics of knowledge accumulation and "creative restructuring"," Industrial and Corporate Change, 24, 565-602.

Zhang, M. And P. Mohnen (2013): "Innovation and survival of new firms in Chinese manufacturing, 2000-2006," MERIT Working Papers 057, UNU-MERIT, Maastricht. 